\title{
Article \\ Spatial Dependence, Social Networks, and Economic Structures in Japanese Regional Labor Migration
}

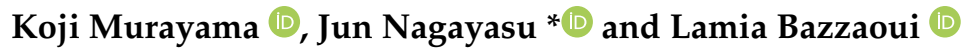 \\ Graduate School of Economics and Management, Tohoku University, Sendai 980-8576, Japan; \\ hakuryu.888@outlook.jp (K.M.); bazzaoui.lamia.a1@tohoku.ac.jp (L.B.) \\ * Correspondence: jun.nagayasu.d8@tohoku.ac.jp
}

Citation: Murayama, K.; Nagayasu, J.; Bazzaoui, L. Spatial Dependence, Social Networks, and Economic Structures in Japanese Regional Labor Migration. Sustainability 2022, 14, 1865. https://doi.org/10.3390/ su14031865

Academic Editors: Stephan Weiler and Sarah A. Low

Received: 5 January 2022

Accepted: 3 February 2022

Published: 6 February 2022

Publisher's Note: MDPI stays neutral with regard to jurisdictional claims in published maps and institutional affiliations.

Copyright: (C) 2022 by the authors. Licensee MDPI, Basel, Switzerland. This article is an open access article distributed under the terms and conditions of the Creative Commons Attribution (CC BY) license (https:// creativecommons.org/licenses/by/ $4.0 /)$.

\begin{abstract}
This study empirically analyzes the determinants of regional labor migration in Japan, where small towns are disappearing due to the shortage of labor. Using spatial models of origindestination flows and considering network effects of labor and economic structures, we obtain results more consistent with the standard migration theory, compared to previous studies. In particular, we find that migration decisions are based on economic motivations and that high (low) unemployment rates in origin (destination) regions and low income in origin regions are important determinants of labor migration flows. Second, we report that network effects, which help reduce migration costs, play a significant role in the relocation of labor. Finally, considering different definitions of spatial weights based on distance, the volume of traded goods, and economic structures, we show that regional dependence is most appropriately defined by the similarity in economic structures. In other words, migration patterns are similar between regions that rely on analogous economic activities.
\end{abstract}

Keywords: labor migration; spatial models; regional economy; economic structures; network effects; job skills

\section{Introduction}

Internal migration has traditionally played an important role in shaping population dynamics and increasing welfare levels by acting as an equilibrating mechanism in the labor market and shifting farming population to more productive urban industrial sectors [1,2]. However, population movements can also be accompanied by negative effects such as increasing regional disparities in terms of income, infrastructure, and well-being, as well as reduction of the standards of living in overpopulated areas and the decline of some industries due to lower factor endowments in some regions [3-5]. Therefore, managing the social and economic risks related to migration requires adequate policies that cannot be formulated without sufficient analyses of real population movements, using scientific methods of migration theory.

In Japan, which has experienced rapid demographic changes, unidirectional movements of labor have increased the rate of urbanization and widened regional heterogeneity. While in 1950, 53\% of the population lived in urban areas, this rate reached $93 \%$ by 2014 [6]. The increased socioeconomic differences between regions are becoming more and more challenging to policymakers who must consider the impacts of macroeconomic policies, designed at the national level, on the different individual regions. These differences also strongly contribute in shaping the spatial distribution of population by affecting interregional migration (see $[7,8])$, as there is a tendency for people to move to urban areas where there are more job opportunities and easier access to medical facilities, shops, and public transportation. As a result, there are many rural regions known as Genkai-shuraku that face depopulation and the risk of disappearing in the near future. The term "Genkaishuraku" or "marginal village" has been popularly recognized in Japan as referring to a rural village facing severe sustainability issues as a result of aging (with at least half of the 
inhabitants aged 65 or more) and depopulation (see [9]). The financial strain faced by local governments in such areas lead to difficulties in various aspects such as the provision of social services and the management of local resources [10]. According to a survey by the Ministry of Agriculture, Forestry and Fisheries [11], the number of these marginal villages reached 13,021 in 2014, among which 1403 of the villages are facing the danger of becoming extinct. This situation creates many risks such as the deterioration of infrastructure and public facilities, isolation of small communities, and various impacts on the environment $[12,13]$. In addition, rural decline represents an economic loss because of the collapse of small industries and the opportunity costs resulting from idle resources [14]. Against this background, understanding the configuration, and determinants of internal migration movements in Japan has become a matter of great importance.

The literature on internal migration in Japan is characterized by a great diversity. Studies differ in terms of their objectives, models, and estimation methodologies. For instance, the authors of $[15,16]$ applied a shift-share analysis to explain migration turnaround episodes in the 1970s and 1980s using demographic factors. Ref. [17] used a gravity model to analyze patterns of migration between Japanese regions based on age groups. Refs. [18,19] used a new economic geography (NEG) model and spatial econometrics methods to test relationships among interregional labor migration and real wages. Ref. [20] used competing destination models [21] to study Japanese inter-municipal migration flows and their relationship with economic conditions. Ref. [22] investigated the relationship between inter-municipal migration and unemployment rates based a spatial model that accounts for interregional dependency, etc.

Despite these diverse approaches, there are some shortcomings that have not yet been addressed in the literature. One of them is the distinction between migration inflows and outflows. Most studies on Japanese internal migration rely on net migration data (e.g., [23-26]). Nevertheless, this approach has been criticized because it does not accurately capture information on the level of migration flows $([27,28])$. More precisely, since net migration corresponds to the difference between in and out migration, it can be equal to zero even though there is massive migration in each direction. Therefore, an analysis of migration patterns based on net migration could lead to biased conclusions. Another limit that has been discussed in [29] is that past studies rarely include intra-regional migration flows or mention how to deal with them. As stated in [30], this situation reflects a view that intraregional flow elements represent a nuisance since the focus of the model is usually on interregional flows. At the same time, setting intraregional flows to zero worsens the precision of spatial models (as demonstrated in [29]). To cope with this issue, an alternative way to deal with intraregional mobility has been suggested by the authors of [31]. In addition to these shortfalls, studies on Japanese internal migration that are based on spatial econometric methods usually rely on a spatial weight matrix defined based on geographical distance (e.g., $[18,19,32])$ without examining the alternative potential specifications that have been considered in this literature (e.g., [33]). Finally, although several determinants of internal migration have been examined in previous studies, the authors of [34] noted that these determinants are usually analyzed separately and rarely combined in a single model.

In the present paper, we analyze the flows of internal labor migration between Japanese prefectures, using data from Japan's National Census between 2005 and 2010, in order to identify their predominant patterns (e.g., rural-urban migration, zones that attract the most flows) and determinants, before the 2011 Tōhoku earthquakes and tsunami. The migration process cannot be easily understood without separating the total population into a set of homogeneous subpopulations and examining their distinctive behaviors, as pointed out in [25]. Therefore, instead of analyzing total population migration, we choose to focus on the migration of the labor force. Choosing to study this group of migrants is also justified by the fact that drawing conclusions on the economic repercussions of workers' migration flows is more straightforward, given that the relationship between labor and the economy is more clearly established (e.g., labor is a key component of households' utility 
in economic theory (for example, see [35])). The existence of this theoretical relationship is important since one of the objectives of our empirical analysis is to examine the impact of economic factors on internal migration.

The present paper contrasts with the previous studies listed above in terms of the research design and the variables included in the model. Our main contribution is the integration of several methodologies of spatial econometrics in a single approach and the use of a model that incorporates social networks, in addition to more frequently studied economic and environmental factors. More specifically, the distinguishing features of our empirical strategy are as follows. First, we use a spatial model that separates between migration inflows and outflows instead of relying on net migration. Second, we distinguish between inter-regional and intra-regional migration flows by using the methodology suggested in [31]. Third, to deal with the issue of spatial spillovers, we model regional dependence based on spatial statistics methods to obtain consistent parameters.

At this stage, our approach departs from previous analyses that usually rely on a single spatial weight matrix based on geographical distance, as we introduce several definitions of regional dependence in the data. In particular, to our knowledge, previous studies on Japanese inter-regional migration have not considered regional heterogeneity in economic structures (Japanese regional heterogeneity is well documented in the economics literature [36-38] but more rarely discussed in the migration literature). Investigating this heterogeneity is important since labor mobility depends on the nature of employment opportunities in the destinations and particularly on the industry-specific skills they require. As discussed by the authors of [39], workers are more likely to transition between occupations requiring similar skills than they are to switch between those requiring dissimilar skills. Therefore, sector and occupation-specific skills have an impact on workers' decisions of mobility (e.g., [40]).

Lastly, we include in our spatial model a relevant set of explanatory variables selected from the prior literature (such as income, population, and amenities like weather conditions). We also incorporate social networks in our model. The authors of [41] showed that social networks play a significant role in migrants' decisions based on data from a survey conducted on young people that moved to the Tokyo area. Still, they also noted that this aspect is usually ignored in the literature on internal migration that focuses more often on economic motives. Then, we estimate the model based on an econometric strategy that deals with the issue of the potential endogeneity of internal migration determinants because labor migration may alter regional economic conditions. In the empirical analysis, we attempt to address the following research questions: What are the main determinants of Japanese internal labor migration over the studied period? How does the inclusion of social networks affect the estimation results? What is the impact of spatial dependence specification on the results? What spatial weight matrix is more adequate to define dependence across Japanese prefectures?

The main findings of our paper point to the prevalence of economic motivations as key determinants of relocation decisions of labor. In addition, the inclusion of social networks improves the fit of the migration model and produces results that are more consistent with theoretical expectations, especially regarding the relationship between economic factors and migration decisions. This is in contrast with some previous studies on Japan, which could not find a congruous link between migrants' decisions and economic variables (e.g., [42]), as they used a different model specification. Finally, our results also show that regional dependence is more adequately defined based on the similarity of economic structures.

The remainder of the paper is organized as follows. In Section 2, we present a brief overview of the main trends in Japanese internal migration. Section 3 provides a summary of the existing literature on migration. A description of the theoretical model, data, and empirical approach used in this study is provided in Section 4. Section 5 presents the main empirical findings. These results are discussed in Section 6. Finally, the last section offers some concluding remarks. 


\section{Main Trends in Japanese Inter-Regional Migration}

For the purpose of this study, we use regional labor migration data from 2010 Japan's National Census [43] (prior to the 2011 Tōhoku earthquakes and tsunami). Based on this database, 10 prefectures contain $56 \%$ of the Japanese population: Tokyo, Kanagawa, Osaka, Aichi, Saitama, Chiba, Hyogo, Hokkaido, Fukuoka, and Shizuoka (more recent data show that this proportion slightly increased to $56.7 \%$ in 2015). The total share of these prefectures was 37\% in 1920. Prefectures with the highest average growth of population over the past century include Kanagawa, Saitama, Chiba, Tokyo, and Osaka. In contrast, the growth of population was the lowest in Shimane, Kochi, Tokushima, Kagoshima, and Yamagata. As a result, the contribution of these prefectures in total population diminished over time. The population of Niigata and Nagano, which was steadily increasing at the beginning of the past century, has almost stagnated since the 1950s. Overall, we note that the evolution of the population distribution in Japan followed the gradual change of the economic structure (growing contribution of the secondary, then the tertiary sector).

The labor force included about 65 million people in 2010, out of which 2 million people were unemployed. Given the Japanese population of 128 million in 2010, this implies that the labor force represents only about a half of the total population. This share is very low by international standards and is explained by the high proportion of elderly citizens. Appendix A shows the percentage of each prefecture in the total number of employees by industry, in addition to the share of each industry in the total number of employees of each prefecture. The largest number of employees in the primary sector is found in Hokkaido, Nagano, Kumamoto, Ibaraki, and Chiba. Over 30\% of the employees in the secondary sector are in Aichi, Tokyo, Kanagawa, Osaka, and Saitama. These prefectures also contain $36.4 \%$ of the employees in the tertiary sector (and they generate about $42 \%$ of total GDP). The contribution of these prefectures is also the largest in almost all component activities of the secondary and tertiary sectors, with the exception of mining, for which the largest share of employees is concentrated in Hokkaido, Niigata, Tokyo, and Chiba. Recent statistics from 2015 [44] show that this structure did not significantly change after 2010.

On the other hand, the distribution of employees by industry in each prefecture indicates that the tertiary sector comprises the largest number of employees in all prefectures. The primary sector appears to be relatively important in terms of employment for Aomori, Iwate, Kochi, and Miyazaki and the secondary sector for Toyama, Shiga, Shizuoka, Gifu, Aichi, and Mie. Regional disparities can also be observed in other statistics. For example, Figure 1 shows the unemployment rate of each prefecture. The highest unemployment rate $(11.9 \%)$ is recorded for Okinawa and the lowest rate (4.24\%), for Fukui. The gap between these regional unemployment rates is about 8 percentage points, implying significant regional disparities in labor market conditions. Additionally, although the unemployment rate in Japan decreased after 2010, these differences across prefectures are still visible with the same patterns as before (maximum rate in Okinawa and minimum in Fukui), according to recent labor force survey data from 2016 [45]. Similarly, there are also substantial differences in income, as shown on Figure 2. The gap between the highest value of real GDP per capita for 2005 (recorded in Tokyo) and the lowest value (in Okinawa) is of JPY 3.13 million. At the end of 2018, this gap is still almost the same (value of JPY 3.02 million based on data from the Cabinet Office [46]).

Net inter-prefectural labor migration in Japan from 2005 to 2010 is depicted in Figure 3. A large amount of labor moved to the Aichi prefecture (a center of the automobile industry) and the Kanto region that includes Tokyo. Within the Kanto region, net labor migration is higher in Saitama, Kanagawa, and Chiba compared to Tokyo because of the high land prices, housing, and living costs.

As illustrated in Figure 4, most migrants are employees in the activities of wholesale and retail trade or in manufacturing. There is also a significant share of employees in health care and in accomodation, eating, and drinking services. This situation applies to almost all prefectures, as shown in Appendix B. 


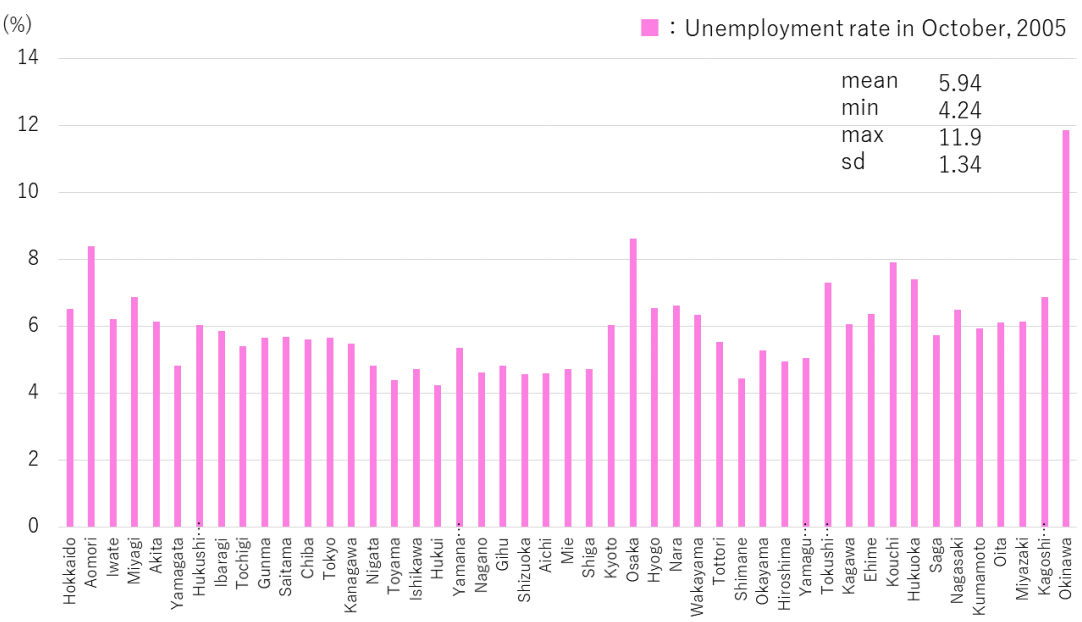

Figure 1. Unemployment rate (\%) in October 2005 (Data from the 2010 Japan Population Census [43]).

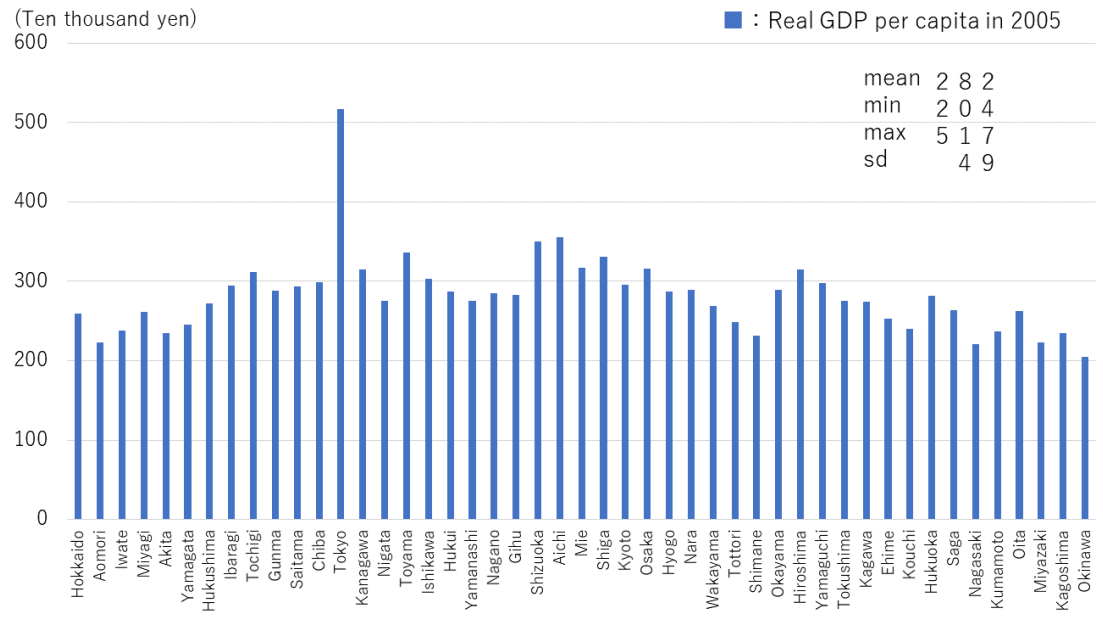

Figure 2. Real GDP per capita (JPY ten thousand) in 2005 (Data from the Cabinet Office [46]).

The nature of predominant economic activities in each prefecture appears to be an important determinant of migration (see Appendix C). For instance, a large share of employees in the primary sector moved to Hokkaido and Nagano, over $30 \%$ of employees in mining to Tokyo or Niigata, and a very significant share of employees in the secondary and tertiary sectors moved to the Kanto region, Osaka or Aichi prefecture. We also notice that Kagoshima prefecture, representing about 3\% of the primary sector labor force in 2010, attracted a significant share of workers in this sector over the studied period. There is also a significant share of workers in the Fisheries sector that moved to Nagasaki.

To compare between migration from urban and rural areas, we rank prefectures based on the density of population per $\mathrm{km}^{2}$ (assuming prefectures with the largest rural area have the lowest density), then look into their characteristics in terms of population growth between 2000 and 2010, economic structure and migration flows between 2005 and 2010. We also include the share of Genkai-shuraku, as reported by the Ministry of Agriculture, Forestry and Fisheries for 2010 [11]. As stated previously, the term Genkai-shuraku refers to marginal rural villages with aging residents (over 50\% aged 65 or above) and a declining population. The result of this comparison is shown in Appendix D. It clearly appears that prefectures with the lowest density of population also have the lowest average population growth, more migrant outflows than inflows, and an economic structure characterized by a relatively significant share of the primary sector. This confirms that there are more emigrants than immigrants in rural areas, as a result of a lower income and fewer job opportunities. In addition, the share of Genkai-shuraku is also relatively more important in prefectures such as Hokkaido, Kochi, Niigata, Tokushima, and Toyama. 
$\quad \quad$ Net labor migration $\leq 0$

$\square: \quad 0<$ Net labor migration $\leq 20000$ $20000<$ Net labor migration $\leq 40000$ $40000<$ Net labor migration

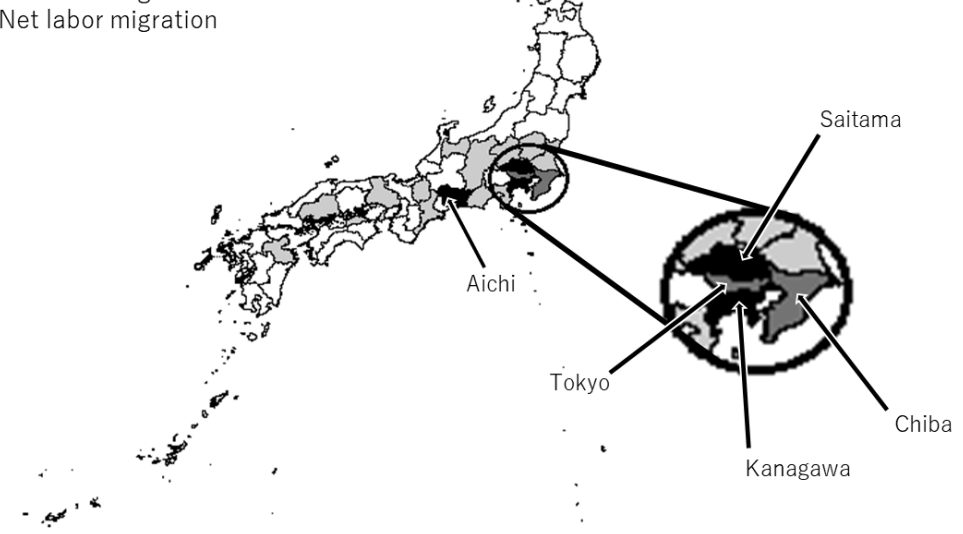

Figure 3. Net labor migration from 2005 to 2010 (Data from the 2010 Japan Population Census [43]).

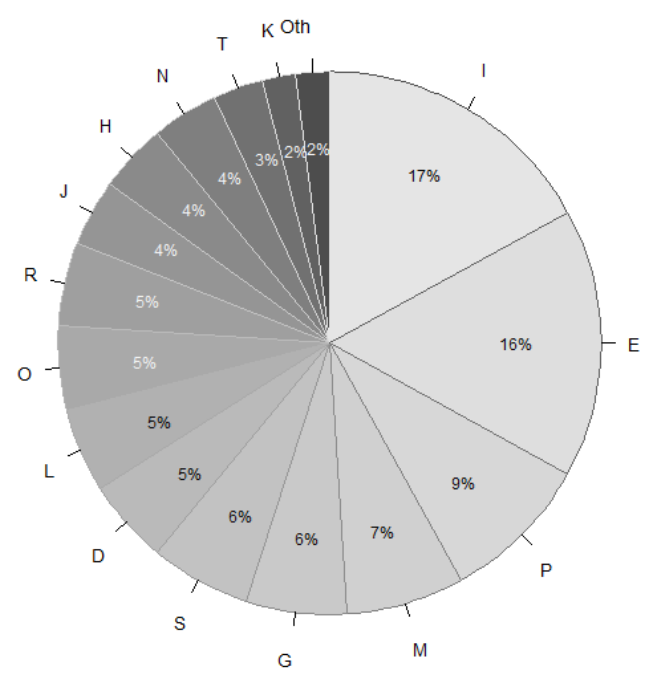

Figure 4. Internal migration flows by economic activity (Data from the 2010 Population Census [43]). Notes: I: wholesale and retail trade; E: manufacturing; P: medical, health care and welfare; M: accommodations, eating and drinking services; G: information and communications; S: government; D: construction; L: scientific research, professional and technical services; O: education, learning support; R: services; J: finance and insurance; $\mathrm{H}$ : transport and postal activities; $\mathrm{N}$ : living-related and personal, amusement services; T: unclassifiable; K: real estate and goods rental, leasing; Oth: includes electricity, gas, heat supply and water, agriculture and forestry, fisheries, mining, and compound services.

\section{Literature Review}

The literature on migration is characterized by a lot of diversity and does not rest on a unified theory or a single statistical approach. As pointed out by the authors of [47], there is not one theory of migration but multiple pieces of theory that explain diverse forms or aspects of migration. Attempts to classify migration studies sometimes distinguish between micro-studies that focus on individuals or households and macro-studies conducted at the aggregate level. Nevertheless, as noted by the authors of [48], the distinction between micro and macro models is often blurred because many aggregate data-based models are derived from theoretical principles that apply to individual decision-making (e.g., the assumption that migrants base their choice decisions of destinations on a cost-benefit calculation of the present value of expected future net returns as in [49]). 
There are also various ways of modeling migration, but the most common approach is the use of spatial interaction models, especially the gravity model that is considered as one of the first formal representations in migration studies [50]. Equation (1) represents the basic formulation of the gravity model.

$$
Y_{o d}=K \frac{X_{o}^{\beta_{1}} X_{d}^{\beta_{2}}}{d_{o d}^{\beta_{3}}},
$$

where $Y_{o d}$ represents migration flows from the origin $(o)$ to the destination $(d), d_{o d}$ the distance between regions, and $X_{o}$ and $X_{d}$ consist of the regional characteristics of $o$ and $d$, respectively, $K$ is a constant, and $\beta_{1}, \beta_{2}, \beta_{3}$ are parameters to be estimated. The model implies that people tend to move to regions close to the origin. In empirical studies, researchers often use the natural logarithm of Equation (1), such that:

$$
\ln Y_{o d}=\ln (K)+\beta_{1} \ln X_{o}+\beta_{2} \ln X_{d}-\beta_{3} \ln d_{o d} .
$$

Other models that can be found in the literature are intervening opportunities models [51-53] and systemic models based on the general theory of movement of [54]. The basic idea behind the intervening-opportunities model is that relocation is directly proportional to the opportunities at the destination and inversely proportional to the number of intervening opportunities between origin and destination zones. In Schneider's model, distance is also a core element as individuals select the closest destination among those with acceptable opportunities. On the other hand, the theory underpinning systemic models offers a new specification of spatial origin-destination flow models, based on a system of equations for flows between regions, total outflow from and total inflow to a region, linked by balancing factors. However, these approaches are not used as frequently because the estimation poses several challenges. For instance, difficulties of intervening opportunities models lie in the practical handling of distance as an ordinal variable, and also in the estimation of parameters in the case of nonlinear specifications (as in Schneider's model). They have however regained popularity recently with the introduction of the radiation approach (see [55]). The general theory of movement is based on a system of simultaneous equations with unobserved balancing factors that need to be estimated (representing opportunities and competition). One of the main issues of the econometric estimation is the dependence between the factors and the correlation with disturbance terms in the system. In contrast, gravity models present several practical advantages and can be easily derived from random utility maximization (RUM) models (see the following section).

Most studies based on spatial interaction models tend to focus on identifying the main determinants of migration by incorporating additional explanatory variables. These variables usually include different characteristics of both origin (push factors) and destination (pull factors) (e.g., [56-58]). Among the explanatory factors that can be found in the literature, a strong empirical support exists for the relevance of economic activity [57,59-61], labor market variables [62-66], environmental variables such as infrastructure, social services, political factors, and natural amenities like the climate [67-69]. As pointed out by the authors of [50], many of the key determinants of migration selected in the recent literature can be traced back to earlier studies on migration. For example, the pioneering work of [70] on the laws of migration had already discussed the prevalence of economic motivations in migrant decisions (as the motive of migration is often the betterment of material conditions), the tendency of migrants to move towards absorption centers (usually large commercial and industrial centers), and the negative correlation with distance. Finally, some recent studies also include social networks as explanatory variables, based on the idea that migrants create networks in the destination places with the effect of reducing costs for new migrants (e.g., $[1,71,72])$.

Another important development of the migration literature lies in the handling of spatial dependence between flows in spatial interaction models. In conventional models, it 
was assumed that using distance as a variable is sufficient to eradicate dependence among origin-destination pairs (OD). However, this view has been challenged with the work of the authors of [73] that showed that the distance parameter is not estimated consistently by usual OLS because spatial autocorrelation effects are confounded with distance decay effects ([74]). Treatment of spatial dependence has been introduced in several subsequent works such as [75-78]. This point is also considered in [79], which provided a detailed account of statistical approaches applied to spatial data (geostatistical, lattice data, and point patterns). Spatial regression models applied to lattice processes in particular, such as spatial autoregressive models (SAR) have also been discussed in [30]. However, the standard SAR models rely on spatial weight structures that model dependence based on observations related to regions instead of pairs of regions. Therefore, the authors of [31] suggested an extension of this class of spatial econometrics to origin-destination flows. They were also able to address the high-dimension problem (high number of OD pairs compared to the number of regions in traditional models) by developing a matrix formulation of the model, more efficient than the typical vectorized formulation.

In the present research, we attempt to uncover the main determinants of Japanese internal migration over the period 2005-2010, using a spatial model of origin-destination flows (see description in the following section). Because of the large quantity of determinants that have been discussed in the literature, it is not possible to include them all in one model. Following the parsimony principle, we select a list of variables that are representative of the aspects that are more likely to affect migration flows (based on the prior literature discussed above). These aspects are economic factors, environmental factors and social networks. At present, there is no consensus in the literature on their effect on internal migration for the particular case of Japan. For example, according to the authors of [80], economic variables such as income and unemployment were seen as crucial determinants for Japanese internal migration before the 1980s, but have lost their power as an explanatory factor since then, which led some authors to search for alternative explanations aside from the economic aspect (e.g., [15,16]). Environmental factors have been examined in many previous studies (e.g., [81,82]). Nonetheless, the authors of [34] noted that they have been rarely combined with human and economic factors in a single model. Finally, as discussed by the authors of [41], the effect of social networks can be important in explaining migration flows but has not been sufficiently investigated in the literature on Japanese internal migration. More details on the included variables are provided in Section 4.2.

\section{Model Framework and Econometric Methodology}

Our analysis is based on a gravity model. We choose this model because it can be easily extended to include explanatory socioeconomic variables for migration flows and also because it allows us to establish a theoretical link between inter- and intra-regional migration. This link was ignored in previous studies that more often excluded intra-regional migration flows $[29,30]$.

\subsection{The Gravity Model}

Following $[59,83,84]$, the gravity model can be derived from a random utility maximization (RUM) model. The RUM approach aims at modeling the choices of individuals among discrete sets of alternatives, based on choice probabilities and utility functions that contain some random elements. Therefore, by using this approach, a micro-foundation is added to the standard gravity model. We proceed as follows. First, using the notation $\ln Y=y$, we define the migration equation as

$$
y_{o d t}=p_{o d t} s_{o t}
$$


where $y_{\text {odt }}$ is the number of migrants who move from $o$ to $d$ at time $t, s_{o t}$ is the population stock in $o$ at $t$, and $p_{o d t} \in[0,1]$ is the proportion of people who move from $o$ to $d$ at $t$. Next, define the utility function of individual $a$ associated with migration as

$$
U_{a o d t}=w_{o d t}-c_{o d t}+\epsilon_{a o d t} \quad d=1, \ldots, n,
$$

where $U_{\text {aodt }}$ is the utility of $a$ arising from migration from $o$ to $d$ at time $t, w_{\text {odt }}$ represents non-stochastic positive effects of migration, $c_{o d t}$ the costs of migration from $o$ to $d$, and $\epsilon_{\text {aodt }}$ corresponds to the stochastic and individual specific components of utility. Then, we can express the probability that individuals will migrate from $o$ to $d$ as $p_{\text {odt }}$, such that:

$$
\begin{aligned}
p_{\text {odt }} & =P\left(U_{\text {aolt }} \leq U_{\text {aodt }}, \forall l \neq d\right) \\
& =P\left(w_{o 1 t}-c_{o 1 t}+\epsilon_{\text {ao1t }} \leq w_{\text {odt }}-c_{\text {odt }}+\epsilon_{\text {aodt }}, \ldots, w_{\text {ont }}-c_{\text {ont }}+\epsilon_{\text {aont }} \leq w_{\text {odt }}-c_{\text {odt }}+\epsilon_{\text {aodt }}\right) \\
& =P\left(\epsilon_{\text {ao1t }} \leq w_{\text {odt }}-c_{o d t}-\left(w_{o 1 t}-c_{o 1 t}\right)+\epsilon_{\text {aodt }}, \ldots, \epsilon_{\text {aont }} \leq w_{\text {odt }}-c_{\text {odt }}-\left(w_{\text {ont }}-c_{\text {ont }}\right)+\epsilon_{\text {aodt }}\right) \\
& =\int_{-\infty}^{\infty} \prod_{\substack{l=1 \\
l \neq d}}^{n} P\left(\epsilon_{\text {aolt }} \leq\left(w_{\text {odt }}-c_{\text {odt }}\right)-\left(w_{\text {olt }}-c_{\text {olt }}\right)+x\right) f_{\epsilon}(x) d x .
\end{aligned}
$$

Furthermore, assuming $\epsilon_{\text {aodt }}$ follows the independent and identically distributed (i.i.d.) Gumbel distribution (type-I extreme value distribution) with parameters $\mu=0$ and $\beta=1$, the cumulative distribution function of $\epsilon$ is

$$
F_{\epsilon}(x)=P\left(\epsilon_{\text {aodt }} \leq x\right)=e^{-e^{-x}} .
$$

Thus, we can express $p_{\text {odt }}$ as

$$
\begin{aligned}
p_{\text {odt }} & =\int_{-\infty}^{\infty} \prod_{\substack{l=1 \\
l \neq d}}^{n} P\left(\epsilon_{\text {aolt }} \leq\left(w_{\text {odt }}-c_{\text {odt }}\right)-\left(w_{\text {olt }}-c_{\text {olt }}\right)+x\right) f_{\varepsilon}(x) d x \\
& =\int_{-\infty}^{\infty} \prod_{\substack{l=1 \\
l \neq d}}^{n} e^{-e^{\left(w_{\text {olt }}-c_{\text {olt }}\right)-\left(w_{\text {odt }}-c_{\text {odt }}\right)-x}} e^{-x} e^{-e^{-x}} d x \\
& =\int_{0}^{\infty} \prod_{\substack{l=1 \\
l \neq d}}^{n} e^{-e^{\left(w_{\text {olt }}-c_{\text {olt }}\right)-\left(w_{\text {odt }}-c_{\text {odt }}\right)} u} e^{-u} d u \\
& =\int_{0}^{\infty} e^{-\left(1+\sum_{\substack{l=1 \\
l \neq d}}^{n} e^{\left(w_{\text {olt }}-c_{\text {olt }}\right)-\left(w_{\text {odt }}-c_{\text {odt }}\right)}\right) u} d u \\
& =\frac{1}{1+\sum_{\substack{l=1 \\
l \neq d}}^{n} e^{\left(w_{\text {olt }}-c_{\text {olt }}\right)-\left(w_{\text {odt }}-c_{\text {odt }}\right)}}=\frac{e^{w_{\text {odt }}-c_{\text {odt }}}}{\sum_{l=1}^{n} e^{w_{\text {olt }}-c_{\text {olt }}}}
\end{aligned}
$$

From Equations (3) and (5), we get:

$$
E\left(y_{\text {odt }}\right)=\frac{e^{w_{\text {odt }}-c_{\text {odt }}}}{\sum_{l=1}^{n} e^{w_{\text {olt }}-c_{\text {olt }}}} s_{\text {ot }} .
$$

Rewriting Equation (6), E( $\left.y_{\text {odt }}\right)$ can be expressed as

$$
E\left(y_{o d t}\right)=\phi_{o d t} \frac{x_{d t}}{\Omega_{o t}} s_{o t},
$$

where $x_{d t}=e^{w_{o d t}}, \phi_{o d t}=e^{-c_{o d t}}$, and $\Omega_{o t}=\sum_{l=1}^{n} \phi_{o l t} x_{l t}$. 
Similarly, $E\left(y_{o o t}\right)$, which represents intra-regional migration, can be expressed as

$$
E\left(y_{o o t}\right)=\phi_{o o t} \frac{x_{o t}}{\Omega_{o t}} s_{o t} .
$$

Now, assuming no living costs in $o$ and $\phi_{\text {oot }}=1$, the ratio of $E\left(y_{\text {odt }}\right)$ to $E\left(y_{o o t}\right)$ can be written as

$$
\frac{E\left(y_{o d t}\right)}{E\left(y_{o o t}\right)}=\phi_{o d t} \frac{x_{d t}}{x_{o t}},
$$

where $\Omega_{o t}$ is canceled out. This equation is the same as the gravity model because the right hand side in Equation (9) is determined by migration costs associated with moving from $o$ to $d\left(\phi_{o d t}\right)$, regional characteristics of the destination $d\left(x_{d t}\right)$, and the origin $o\left(x_{o t}\right)$. Taking the natural logarithmic form, we obtain a specification consistent with Equation (2).

$$
\ln \left(\frac{E\left(y_{o d t}\right)}{E\left(y_{o o t}\right)}\right)=\ln x_{d t}-\ln x_{o t}+\ln \phi_{o d t},
$$

where $\ln x_{d t}, \ln x_{o t}$, and $\ln \phi_{o d t}$ correspond to $\ln X_{d}, \ln X_{o}$, and $\ln d_{o d}$ in Equation (2), respectively. In the following section, we discuss the elements to include in the matrices of regional characteristics $x_{d t}$ and $x_{o t}$ in the present study.

\subsection{Determinants of Migration}

The matrices of regional characteristics in Equation (10) represent the push and pull factors for migration that have been previously discussed in the literature. In the present study, we select the following list of explanatory variables as they have been repeatedly reported to affect relocation decisions of labor.

- Gravity variables: The standard gravity variables are the population size and distance. Population can be either a push factor (more emigrants from populated zones) or an attractive determinant if population is viewed as a proxy for market size, in which case migration will be higher to populated regions because of the greater number of employment opportunities [85]. Distance is considered as a fundamental explanatory variable that proxies the migration costs (transportation and information). According to the authors of [86], omitting distance can seriously bias empirical findings.

- Income: Since the first migration studies, economic activity has always been considered as an important determinant. In the present paper, we use real GDP per capita as a proxy for income. The previous literature provides strong evidence for the impact of this variable on migration flows (e.g., [19,57]).

- Unemployment rates: Labor market conditions are, probably, the most popular explanation of labor migration in previous studies. However, as opposed to income, the empirical literature suggests that the impact of unemployment on internal migration is not clear. While some studies consider the unemployment rate to be an important determinant [87-89], others failed to find a significant relationship (e.g., [42,90]).

- Amenities: Topological, climatological, and environmental amenities are often considered as important factors in migrant decisions [57]. We include two climate variables that are more relevant for the Japanese case: temperature and precipitation. It is assumed that migrants would prefer regions with a higher temperature and a lower level of precipitation [91].

- Network effects: Social networks represent family members, kinship groups, or migrants from the same origin. Previous studies reported the effects of these networks on migrants' decision-making. In particular, it is believed that these networks encourage migration to specific destinations since they reduce the costs and uncertainty of the migration process and thereby facilitate it $[1,85,92,93]$. They can also induce migration through demonstration effects [94]. The presence of social networks can be proxied by past migration. 


\subsection{Spatial Dependence in a Model of Origin-Destination Flows}

Unlike many previous studies that focus on net migration flows (e.g., $[18,25,26]$ ), we distinguish between origin and destination regions. The separate treatment of origin and destination flow is important because a large flow in one particular direction (say, from an origin $o$ to a destination $d$ ) will be ignored in the analysis if it is offset by a large flow in the opposite direction (from the destination $d$ to the origin $o$ ). As it becomes clear in this study, such a distinction in migration flows helps us in better capturing the drivers of labor movements. In addition, we also distinguish between inter-prefectural and intra-prefectural migration. As discussed previously in $[29,95]$, if the distinction between inter-regional and intra-regional flows is not made, parameters may be estimated to explain intra-regional flows, which are often larger than inter-regional flows. One way to deal with this issue is by embedding a separate model for intra-regional flows (see [31]). The spatial model of origin-destination flows used in this paper is based on the gravity equation derived previously, extended to account for spatial dependence. Formally, the model is expressed as follows:

$$
y_{o d}=\rho_{o} W_{o} y_{o d}+\rho_{d} W_{d} y_{o d}+\iota_{N} \alpha+X_{o} \beta_{o}+X_{d} \beta_{d}+d i s t_{o d} \gamma+X_{i} \beta_{i}+\varepsilon,
$$

where $y_{o d}$ is an $N \times 1$ matrix representing labor migration flows $\left(N=n^{2}\right)$ and $n$ is the number of regions. $\iota_{N}$ is an $N \times 1$ matrix and consists of unity, and $\alpha$ is an intercept. $X_{o}$ is an $N \times k$ matrix of $o^{\prime}$ s characteristics and $X_{d}$ is an $N \times k$ matrix of $d^{\prime}$ 's characteristics whose elements are zero when corresponding dependent variables represent intra-prefectural migration. Thus, $X_{o}$ and $X_{d}$ have no effects on intra-prefectural migration. $X_{i}$ is an $N \times l$ matrix where elements are zero if corresponding dependent variables capture inter-prefectural migration and take some values of particular regions when corresponding dependent variables represent intra-prefectural migration. In this study, we use past intra-migration data as $X_{i}$. dist ${ }_{o d}$ is an $N_{1} \times 1$ matrix and measures the distance between $o$ and $d$ if the corresponding dependent variable is an inter-prefectural migration but is zero otherwise. $\varepsilon$ is an $N \times 1$ disturbance, $\rho_{d}$ and $\rho_{o}$ represent the strength of spatial dependence, and $\beta_{0}, \beta_{d}, \gamma$, $\delta$ and $\alpha_{i}$ are parameters.

$W_{o}$ and $W_{d}$ are spatial weight matrixes that represent the origin- and the destinationbased spatial dependence, respectively. The origin-based spatial dependence $\left(W_{o}\right)$ measures the level of strength between migration from an origin region to a particular destination and migration from the neighbors of the origin region to the same destination. It captures the fact that migration flows from $o$ to $d$ are affected (i) strongly by migration from 'regions near $o^{\prime}$ to ' $d$ ' and (ii) weakly by migration from 'regions distant from $o^{\prime}$ to ' $d$.' This is illustrated in Figure 5, where the degree of spatial correlation is expressed by the thickness of gray arrows from neighbor origins to the destination. The figure depicts the idea that the migration flow from a given origin region $o$ to destination ' $d$ ' is more correlated with the migration flow from 'regions near $o^{\prime}$ such as $A$ to ' $d$ ' than with the migration flow from 'regions distant from $o^{\prime}$ to ' $d$ ' (such as $B$ ).

On the other hand, the destination-based dependence $\left(W_{d}\right)$ measures the relationship between migration from $o$ to $d$ and migration from $o$ to the destination's neighbor. $W_{d}$ indicates that migration from $o$ to $d$ is affected (i) strongly by migration flows from ' $O$ ' to 'regions near $d$ ' and (ii) weakly by migration from ' $o$ ' to 'regions distant from $d$ '. As shown in Figure 6, the spatial correlation of migration from ' $o$ ' to ' $d$ ' with migration from ' $o$ ' to 'regions near $d$ ', is greater than with migration from ' $o$ ' to 'regions distant from $d$ ' (expressed by a thin gray arrow from $o$ to $D$ ).

For illustrative purposes, let us consider three regions, $a, b$, and $c$ to explain $W$. In this example, a vector of dependent variables becomes $y_{o d}=\left[y_{a a}, y_{a b}, y_{a c}, y_{b a}, y_{b b}, y_{b c}\right.$, $\left.y_{c a}, y_{c b}, y_{c c}\right]^{\prime}$, where $y_{a a}$ is the intra-regional migration within $a$, and $y_{a b}$ shows inter-regional migration from $a$ to $b$. In the context of three regions, $W$ can be expressed as 


$$
W=\left(\begin{array}{ccc}
0 & w_{a b} & w_{a c} \\
w_{b a} & 0 & w_{b c} \\
w_{c a} & w_{c b} & 0
\end{array}\right)
$$

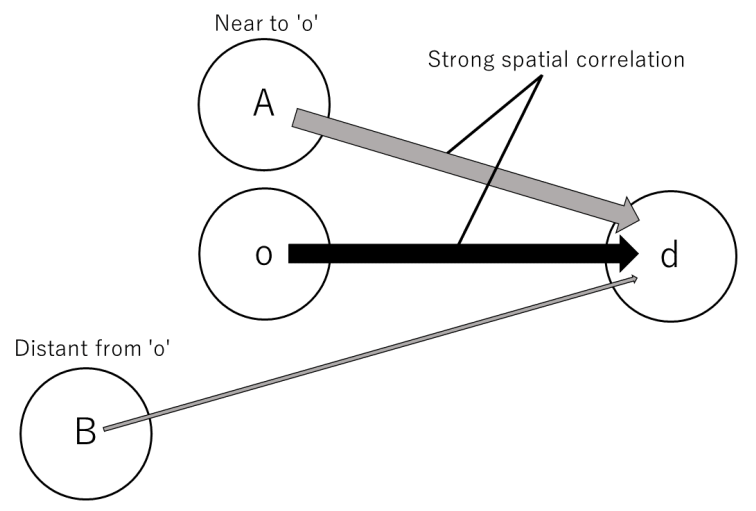

Figure 5. Origin-based dependence of $y_{o d}$. (Source: made by the authors).

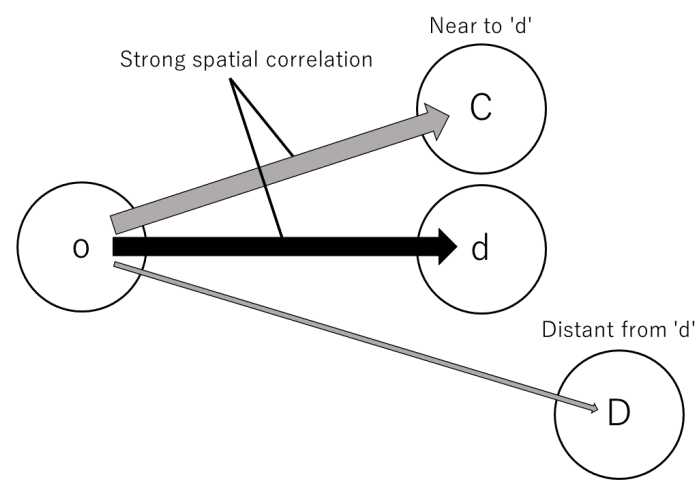

Figure 6. Destination -based dependence of $y_{o d}$. (Source: made by the authors).

The elements in $W$ indicate the strength of the contiguity between regions, and the sum of rows of $W$ is normalized. Thus, the origin-based spatial weight $W_{o}$ can be expressed as $W_{o}=W \otimes I_{n}$.

$$
W_{o}=\left(\begin{array}{ccc}
0 & w_{a b} & w_{a c} \\
w_{b a} & 0 & w_{b c} \\
w_{c a} & w_{c b} & 0
\end{array}\right) \otimes I_{n}=\left(\begin{array}{ccc}
\mathbf{0} & w_{a b} I_{n} & w_{a c} I_{n} \\
w_{b a} I_{n} & \mathbf{0} & w_{b c} I_{n} \\
w_{c a} I_{n} & w_{c b} I_{n} & \mathbf{0}
\end{array}\right)
$$

Therefore, $W_{o} y_{o d}$ can be denoted as

$$
W_{o} y_{o d}=\left(\begin{array}{ccccccccc}
0 & 0 & 0 & w_{a b} & 0 & 0 & w_{a c} & 0 & 0 \\
0 & 0 & 0 & 0 & w_{a b} & 0 & 0 & w_{a c} & 0 \\
0 & 0 & 0 & 0 & 0 & w_{a b} & 0 & 0 & w_{a c} \\
w_{b a} & 0 & 0 & 0 & 0 & 0 & w_{b c} & 0 & 0 \\
0 & w_{b a} & 0 & 0 & 0 & 0 & 0 & w_{b c} & 0 \\
0 & 0 & w_{b a} & 0 & 0 & 0 & 0 & 0 & w_{b c} \\
w_{c a} & 0 & 0 & w_{c b} & 0 & 0 & 0 & 0 & 0 \\
0 & w_{c a} & 0 & 0 & w_{c b} & 0 & 0 & 0 & 0 \\
0 & 0 & w_{c a} & 0 & 0 & w_{c b} & 0 & 0 & 0
\end{array}\right)\left(\begin{array}{l}
y_{a a} \\
y_{a b} \\
y_{a c} \\
y_{b a} \\
y_{b b} \\
y_{b c} \\
y_{c a} \\
y_{c b} \\
y_{c c}
\end{array}\right)=\left(\begin{array}{l}
w_{a b} y_{b a}+w_{a c} y_{c a} \\
w_{a b} y_{b b}+w_{a c} y_{c b} \\
w_{a b} y_{b c}+w_{a c} y_{c c} \\
w_{b a} y_{a a}+w_{b c} y_{c a} \\
w_{b a} y_{a b}+w_{b c} y_{c b} \\
w_{b a} y_{a c}+w_{b c} y_{c c} \\
w_{c a} y_{a a}+w_{c b} y_{b a} \\
w_{c a} y_{a b}+w_{c b} y_{b b} \\
w_{c a} y_{a c}+w_{c b} y_{b c}
\end{array}\right),
$$

where, for example, the origin-based dependence of the migration flow $y_{a}$ from $a$ to $a$ is measured by $w_{a b} y_{b a}+w_{a c} y_{c a}$ which corresponds to the sum of all other flows to the same 
destination $d$, weighted by a matrix that represents the proximity of the respective origin regions with the origin $a$. Similarly, the origin-based dependence of $y_{a b}$ is captured by $w_{a b} y_{b b}+w_{a c} y_{c b}$. Concretely, including $W_{o} y_{o d}$ in the model could be useful to capture, for example, the correlation between flows from a given prefecture to Tokyo (a typical attractive destination for labor) and weighted migration flows from other prefectures to Tokyo.

Similarly, the destination-based spatial weight matrix $\left(W_{d}\right)$ can be defined as $W_{d}=$ $I_{n} \otimes W$; that is,

$$
W_{d}=\left(\begin{array}{ccc}
1 & 0 & 0 \\
0 & 1 & 0 \\
0 & 0 & 1
\end{array}\right) \otimes W=\left(\begin{array}{ccc}
W & \mathbf{0} & \mathbf{0} \\
\mathbf{0} & W & \mathbf{0} \\
\mathbf{0} & \mathbf{0} & W
\end{array}\right) .
$$

Therefore, $W_{d} y_{o d}$ becomes

$$
W_{d} y_{o d}=\left(\begin{array}{ccccccccc}
0 & w_{a b} & w_{a c} & 0 & 0 & 0 & 0 & 0 & 0 \\
w_{b a} & 0 & w_{b c} & 0 & 0 & 0 & 0 & 0 & 0 \\
w_{c a} & w_{c b} & 0 & 0 & 0 & 0 & 0 & 0 & 0 \\
0 & 0 & 0 & 0 & w_{a b} & w_{a c} & 0 & 0 & 0 \\
0 & 0 & 0 & w_{b a} & 0 & w_{b c} & 0 & 0 & 0 \\
0 & 0 & 0 & w_{c a} & w_{c b} & 0 & 0 & 0 & 0 \\
0 & 0 & 0 & 0 & 0 & 0 & 0 & w_{a b} & w_{a c} \\
0 & 0 & 0 & 0 & 0 & 0 & w_{b a} & 0 & w_{b c} \\
0 & 0 & 0 & 0 & 0 & 0 & w_{c a} & w_{c b} & 0
\end{array}\right)\left(\begin{array}{l}
y_{a a} \\
y_{a b} \\
y_{a c} \\
y_{b a} \\
y_{b b} \\
y_{b c} \\
y_{c a} \\
y_{c b} \\
y_{c c}
\end{array}\right)=\left(\begin{array}{l}
w_{a b} y_{a b}+w_{a c} y_{a c} \\
w_{b a} y_{a a}+w_{b c} y_{a c} \\
w_{c a} y_{a a}+w_{c b} y_{a b} \\
w_{a b} y_{b b}+w_{a c} y_{b c} \\
w_{b a} y_{b a}+w_{b c} y_{b c} \\
w_{c a} y_{b a}+w_{c b} y_{b b} \\
w_{a b} y_{c b}+w_{a c} y_{c c} \\
w_{b a} y_{c a}+w_{b c} y_{c c} \\
w_{c a} y_{c a}+w_{c b} y_{c b}
\end{array}\right) .
$$

For instance, $w_{a b} y_{a b}+w_{a c} y_{a c}$ represents the destination-based dependence of the migration flow $y_{a a}$ from $a$ to $a$. It corresponds to the sum of all other flows from the same origin $a$ to other destinations, weighted by the degree of proximity between the destination $a$ and these other destinations. Similarly, the destination-based dependence of $y_{a b}$ is $w_{b a} y_{a a}+w_{b c} y_{a c}$. It represents the sum of other flows from the same origin (from $a$ to $a$ and from $a$ to $c$ ), weighted by a matrix that captures the proximity between the destination $b$ and the other destinations $a$ and $c$, respectively $\left(w_{b a}\right.$ and $\left.w_{b c}\right)$. By way of example, $W_{d} y_{o d}$ could be used to represent the dependence between flows from a given prefecture to Tokyo and flows from the same prefecture to other prefectures in the Kanto region (e.g., Chiba, Saitama).

\subsection{Spatial Weight Matrixes}

We have highlighted the importance of spatial dependence in migration studies, but what are the elements of $W$ (that is, $w$ ) that determine the definition of neighbors? The majority of previous studies used geographical distances by assuming that the proximity of regions affects the likelihood of labor movements between them. In this paper, we use three alternative definitions of the spatial weight matrix, based on: (i) the distance between prefectural capitals, (ii) the flow of goods, and (iii) the similarity in economic structures.

The first definition of the spatial weight is based on the geographical distance between two regions (in the present case between prefectural capitals). Let us define a $47 \times 47$ spatial weight matrix $W$ consisting of the elements $w_{i j}$, with:

$$
w_{i j}= \begin{cases}\frac{\operatorname{dist}_{i j}^{-p}}{\sum_{j=1}^{47} d_{i s t_{i j}^{-p}}}, & \text { if } i \neq j \\ 0, & \text { otherwise, }\end{cases}
$$

where dist $_{i j}$ is the distance between prefectural capitals, and $p$ can take any real positive value (we use $p=1,2$, or 3 in this study). Then, we can construct spatial weight matrixes using the Kronecker product such that $W_{o}=W \otimes I$ and $W_{d}=I \otimes W$, where $I$ is a $47 \times 47$ 
identity matrix. This definition of the weight matrix implies that spatial dependence increases with the physical proximity between regions.

The second definition of spatial weight matrixes is based on the volume of goods traded between regions. We use this approach because there are three metropolitan areas in Japan (Tokyo, Osaka, and Aichi) to which many people and goods flow even from distant rural regions. Therefore, we expect that migration flows to (or from) these commercial and industrial centers will have more impact on other OD flows, compared to flows to (or from) less dynamic remote regions. We define a $47 \times 47$ spatial weight matrix $W$, with a normalized sum of rows, consisting of elements $w_{i j}$, with:

$$
w_{i j}^{g}= \begin{cases}\frac{\left(g_{i j, t-1}+g_{j i, t-1}\right)}{\sum_{j=1}^{47}\left(g_{i j, t-1}+g_{j i, t-1}\right)}, & \text { if } i \neq j \\ 0, & \text { otherwise, }\end{cases}
$$

where $g_{i j, t-1}$ corresponds to the past flow of goods between $i$ and $j$. This expression implies a greater dependence between regions with a larger volume of traded goods.

The third definition of spatial weight matrixes reflects the similarity between prefectures in terms of the economic structure. We measure this similarity based on the shares of the primary, secondary, and tertiary sectors in the total number of firms and total GDP for each prefecture. Assuming that each economic sector calls for labor with industryspecific skills, then there will be a similarity in terms of the size and qualification of labor migration flows across regions with the same economic structure. We define $W$ as a $47 \times 47$ spatial weight matrix (with a normalized sum of rows) that consists of the elements $w_{i j}^{s}$. First, we determine $w_{i j}^{s}$ on the basis of the share of the primary sector in the economy, such that:

$$
w_{i j}^{s 1}= \begin{cases}\frac{1-\left|s 1_{i}-s 1_{j}\right| /\left(s 1_{i}+s 1_{j}\right)}{\sum_{j=1}^{47}\left(1-\left|s 1_{i}-s 1_{j}\right| /\left(s 1_{i}+s 1_{j}\right)\right)}, & \text { if } i \neq j \\ 0, & \text { otherwise, }\end{cases}
$$

where $s 1_{i}$ and $s 1_{j}$ are ratios of the number of firms or GDP of the primary industry to that of all industries in $i$ and $j$, respectively. The specification à la $1-\left|A_{i}-A_{j}\right| /\left(A_{i}+A_{j}\right)$ is from [96]. This expression becomes large if regional characteristics are similar. Thus, $w_{i j}^{s 1}$ grows larger if the weight of the primary industry in the economy of prefecture $i$ is analogous to the one in prefecture $j$. Alternatively, we can construct a spatial weight matrix for the secondary and tertiary sectors. The elements of the weight matrix in these cases are:

$$
\begin{aligned}
& w_{i j}^{s 2}= \begin{cases}\frac{1-\left|s 2_{i}-s 2_{j}\right| /\left(s 2_{i}+s 2_{j}\right)}{\sum_{j=1}^{47}\left(1-\left|s 2_{i}-s 2_{j}\right| /\left(s 2_{i}+s 2_{j}\right)\right)}, & \text { if } i \neq j \\
0, & \text { otherwise, }\end{cases} \\
& w_{i j}^{s 3}= \begin{cases}\frac{1-\left|s 3_{i}-s 3_{j}\right| /\left(s 3_{i}+s 3_{j}\right)}{\sum_{j=1}^{47}\left(1-\left|s 3_{i}-s 3_{j}\right| /\left(s 3_{i}+s 3_{j}\right)\right)}, & \text { if } i \neq j \\
0, & \text { otherwise, }\end{cases}
\end{aligned}
$$

where $s 2_{i}$ and $s 2_{j}$ are ratios of the number of firms or GDP of the secondary industry to the total of all industries in $i$ and $j$. Similarly, $s 3_{i}$ and $s 3_{j}$ are the shares of the tertiary sector in the economy of $i$ and $j$ respectively, in terms of the number of firms or GDP. Finally, the elements of the spatial weight matrix based on the overall economic structure can be expressed as:

$$
w_{i j}^{s 123}= \begin{cases}\frac{S_{123}}{\sum_{j=1}^{47} S_{123}}, & \text { if } i \neq j \\ 0, & \text { otherwise }\end{cases}
$$


where $S_{123}=1-\left\{\left|s 1_{i}-s 1_{j}\right| /\left(s 1_{i}+s 1_{j}\right)+\left|s 2_{i}-s 2_{j}\right| /\left(s 2_{i}+s 2_{j}\right)+\left|s 3_{i}-s 3_{j}\right| /\left(s 3_{i}+s 3_{j}\right)\right\} / 3$, and $w_{i j}^{s 123}$ becomes large if the economic structure is homogeneous between prefectures.

\subsection{Data and Methodology}

Our dataset covers 47 regions (prefectures) that comprise Japan. Regional labor migration data are obtained from Japan's National Census (Kokusei Chosa) in 2010 (as of this writing, this is the most recent data disseminated to the public). Thus, unusual labor movements due to the 2011 earthquakes and tsunami are not covered here. The Census is the most comprehensive dataset that collects details of residents in Japan and has been conducted every five years. Migrant labor refers to labor who relocated residence from one prefecture to the other in the past five years (the National Census was conducted in October). The labor force consists of the employed and unemployed, the employed are those older than 15 years and gain income, and the unemployed are those seeking jobs.

Additional data are collected from various sources. Real GDP per capita, which is a proxy for income, is obtained from the Japanese Cabinet Office and is equal to the nominal GDP per capita (JPY 1000) in 2005 divided by GDP deflator in 2005. Unemployment rates $(\%)$ and the regional population between the ages of 10 and 70 are calculated from the 2005 National Census. Regional temperatures $\left({ }^{\circ} \mathrm{C}\right)$ are the average temperatures between 2005 and 2010. Regional precipitation data $(\mathrm{mm})$ correspond to the amount of annual precipitation in each prefecture for 2005, and are obtained from the Statistics Bureau, Ministry of Internal Affairs and Communications (MIAC). Social networks are from the MIAC and are proxied by the number of cumulative human migration between prefectures from October 2000 to September 2005.

To construct spatial weights, the geographical distance between prefectures is obtained from Japan's Geospatial Information Authority. Furthermore, regional flows of goods (quantity unit) in 2005, GDP in 2005, and the number of firms in 2004 are collected from the Ministry of Land, Infrastructure, and Transport; the Japanese Cabinet Office, and the MIAC, respectively, in order to construct the different definitions of neighbors. Distance is, obviously, exogenous in the model. Similarly, since the dependent variable is labor migration from October 2005 to October 2010, past flows of traded goods in 2005, and indices of the economic structure for 2004 and 2005 are also exogenous. Finally, some descriptive statistics of the data are presented in Table 1.

Using this dataset, we first estimate a non-spatial model for Japanese internal migration using Ordinary Least Squares (OLS). Then, following [31], we construct a spatial regime model and estimate it using S2SLS (Spatial Two Stage Least Squares). Spatially lagged variables $W_{o} y_{o d}, W_{d} y_{o d}$ in this study may be endogenous in the migration function. Therefore, the use of S2SLS is more appropriate, as pointed out by the authors of [97]. Defining $Z$ as consisting of all exogenous explanatory variables in the model, instrumental variables of endogenous variables $W_{o} y_{o d}$ and $W_{d} y_{o d}$ are, thus, $H=$ $\left(Z, W_{o} Z, W_{d} Z, W_{o} W_{d} Z, W_{o}^{2} Z, W_{d}^{2} Z\right)$. Estimation results are discussed in the following.

Table 1. Descriptive statistics.

\begin{tabular}{lcccc}
\hline & Mean & SD & Min & Max \\
\hline Inter- and intra-prefectural migration & 6.28 & 1.81 & 2.48 & 13.9 \\
Unemployment rates of prefectures & 5.94 & 1.36 & 4.24 & 11.9 \\
Real GDP per capita of prefectures & 7.93 & 0.16 & 7.62 & 8.55 \\
No. of population of prefectures & 14.2 & 0.77 & 13.0 & 16.1 \\
Average annual temperature of prefectures & 2.73 & 0.16 & 2.23 & 3.15 \\
Annual precipitation of prefectures & 7.34 & 0.25 & 6.87 & 7.82 \\
Past inter-prefectural migration & 7.36 & 1.61 & 2.64 & 12.9 \\
Distance between prefectures & 5.98 & 0.80 & 2.35 & 7.72 \\
Past intra-prefectural migration & 12.2 & 0.93 & 10.8 & 14.5 \\
\hline
\end{tabular}

Note: Standard deviation (SD). All variables are in natural log except unemployment rates that are expressed in terms of percentage. 


\section{Empirical Results}

\subsection{Results from Non-Spatial Models}

Initially, we estimate a cross-sectional migration model using OLS and without accounting for spatial dependence. Maintaining the notations of variables used in Equation (11), we add the variable $\bar{z}_{o d, t-1}$ as a proxy for social networks.

$$
y_{o d}=\iota_{N} \alpha+X_{o} \beta_{o}+X_{d} \beta_{d}+\text { dist }_{o d} \gamma+\bar{z}_{o d, t-1} \delta+X_{i} \beta_{i}+\varepsilon .
$$

The OLS results with and without social network effects are reported in Table 2. We find that most parameters are statistically significant. In line with expectations, there is a negative relationship between distance and migration. The population size in both origin and destination prefectures has a positive effect. The impact of amenities varies depending on the model specification (with or without social networks). The variable of social networks is in turn important in explaining inter-regional migration with a fairly large parameter (0.977). This finding suggests that human relationships are important factors in relocation decisions and contribute in increasing labor migration.

In addition, we note that the treatment of social networks influences empirical outcomes for some explanatory variables, and this can be seen clearly in the Table. For example, in Column (A), which does not control for social networks, income in both $o$ and $d$ has a negative and significant effect on labor migration. This result, which implies labor moves to low-income destinations, is inconsistent with the previous theoretical and empirical literature. In contrast, in Column (B), where social network effects are included, income in $o$ has a negative and significant effect, and income in $d$ has a positive and insignificant effect on labor migration. This result is closer to theoretical predictions. Similarly, Column (A) shows that the temperature and precipitation rate of both origin and destination prefectures have a positive impact, which is counterintuitive. On the other hand, in Column (B), it appears that migrants tend to move from colder to warmer prefectures and to favor destinations with a lower amount of precipitation. Finally, we also note that the Akaike Information Criterion (AIC) in (B) is smaller than the one in (A), implying a larger information loss in the (A) model. Therefore, we conclude that incorporating social networks improves the model performance significantly. Next, we assess the impact of spatial dependence.

Table 2. OLS results for migration equations.

\begin{tabular}{lcc}
\hline $\begin{array}{l}\text { Dependent Variable: Log of Inter-Prefectural Labor Migration } \\
\text { Explanatory Variable }\end{array}$ & (A) & (B) \\
\hline Intercept & $-6.656^{* * *}$ & -0.146 \\
& $(0.952)$ & $(0.300)$ \\
Unemployment rate_o & $0.063^{* * *}$ & $0.012^{* *}$ \\
& $(0.014)$ & $(0.004)$ \\
Unemployment rate_d & -0.025 & $-0.068^{* * *}$ \\
& $(0.014)$ & $(0.004)$ \\
Real GDP per capita_o & $-1.458^{* * *}$ & $-0.143^{* * *}$ \\
Real GDP per capita_d & $(0.116)$ & $(0.037)$ \\
& $-1.075^{* * *}$ & 0.014 \\
No. of population_o & $(0.116)$ & $(0.037)$ \\
& $1.232^{* * *}$ & $0.026^{*}$ \\
No. of population_d & $(0.023)$ & $(0.011)$ \\
Average temperature_o & $1.280^{* * *}$ & $0.027^{*}$ \\
Average temperature_d & $(0.023)$ & $(0.011)$ \\
& $0.017^{* * *}$ & $-0.012^{* * *}$ \\
\hline
\end{tabular}


Table 2. Cont.

\begin{tabular}{lcc}
\hline $\begin{array}{l}\text { Dependent Variable: Log of Inter-Prefectural Labor Migration } \\
\text { Explanatory Variable }\end{array}$ & (A) & (B) \\
\hline Annual precipitation_o & $0.318^{* * *}$ & $0.082^{* * *}$ \\
& $(0.060)$ & $(0.019)$ \\
Annual precipitation_d & $0.168^{* *}$ & $-0.084^{* * *}$ \\
& $(0.060)$ & $(0.019)$ \\
Social network effects & $0.977^{* * *}$ & \\
& $(0.007)$ & \\
Distance between prefectures & $-1.114^{* * *}$ & $-0.046^{* * *}$ \\
& $(0.018)$ & $(0.009)$ \\
Past intra-prefectural migration & $1.518^{* * *}$ & $0.990^{* * *}$ \\
& $(0.078)$ & $(0.024)$ \\
\hline Sample size & 2209 & 2209 \\
AIC & 4128.083 & -1025.536 \\
\hline Note: ${ }^{* * *} p<0.001,{ }^{* *} p<0.01,^{*} p<0.05$. Subscripts 'o' and 'd' represent origin and destination regions, \\
respectively. & & \\
\end{tabular}

\subsection{Results from Spatial Models}

After constructing the weight matrices as described above, we proceed with a test of the presence of global spatial relationships, using the Moran's I test for migration. Results are reported in Table 3. Since the null hypotheses are rejected ( $p$-value $<0.001$ ) for all spatial matrixes, we confirm that labor migration in Japan is spatially interactive as stated above. We then estimate the model based on the different regional dependence specifications.

Table 3. Moran's I tests for migration.

\begin{tabular}{|c|c|c|c|c|}
\hline Spatial Weight Matrix & Moran's I Statistic & Expectation & SD & $p$-Value \\
\hline$W_{o}$ (Inverse-distance) & 0.411 & -0.0005 & 0.0064 & 0.000 \\
\hline$W_{d}$ (Inverse-distance) & 0.454 & -0.0005 & 0.0064 & 0.000 \\
\hline$W_{o}$ (Square of inverse-distance) & 0.603 & -0.0005 & 0.0122 & 0.000 \\
\hline$W_{d}$ (Square of inverse-distance) & 0.626 & -0.0005 & 0.0122 & 0.000 \\
\hline$W_{o}$ (Cubic form of inverse-distance) & 0.691 & -0.0005 & 0.0167 & 0.000 \\
\hline$W_{d}$ (Cubic form of inverse-distance) & 0.704 & -0.0005 & 0.0167 & 0.000 \\
\hline$W_{o}$ (Past goods flow) & 0.422 & -0.0005 & 0.0081 & 0.000 \\
\hline$W_{d}$ (Past goods flow) & 0.467 & -0.0005 & 0.0081 & 0.000 \\
\hline$W_{o}$ (Primary industry_establishments) & 0.241 & -0.0005 & 0.0046 & 0.000 \\
\hline$W_{d}$ (Primary industry_establishments) & 0.292 & -0.0005 & 0.0046 & 0.000 \\
\hline$W_{o}$ (Secondary industry_establishments) & 0.210 & -0.0005 & 0.0044 & 0.000 \\
\hline$W_{d}$ (Secondary industry_establishments) & 0.269 & -0.0005 & 0.0044 & 0.000 \\
\hline$W_{o}$ (Tertiary industry_establishments) & 0.208 & -0.0005 & 0.0044 & 0.000 \\
\hline$W_{d}$ (Tertiary industry_establishments) & 0.267 & -0.0005 & 0.0044 & 0.000 \\
\hline$W_{o}$ (All industries_establishments) & 0.215 & -0.0005 & 0.0044 & 0.000 \\
\hline$W_{d}$ (All industries_establishments) & 0.272 & -0.0005 & 0.0044 & 0.000 \\
\hline$W_{o}$ (Primary industry_GDP) & 0.264 & -0.0005 & 0.0048 & 0.000 \\
\hline$W_{d}$ (Primary industry_GDP) & 0.309 & -0.0005 & 0.0048 & 0.000 \\
\hline$W_{o}$ (Secondary industry_GDP) & 0.207 & -0.0005 & 0.0044 & 0.000 \\
\hline$W_{d}$ (Secondary industry_GDP) & 0.266 & -0.0005 & 0.0044 & 0.000 \\
\hline$W_{o}$ (Tertiary industry_GDP) & 0.208 & -0.0005 & 0.0044 & 0.000 \\
\hline$W_{d}$ (Tertiary industry_GDP) & 0.266 & -0.0005 & 0.0044 & 0.000 \\
\hline$W_{o}$ (All industries_GDP) & 0.216 & -0.0005 & 0.0044 & 0.000 \\
\hline$W_{d}$ (All industries_GDP) & 0.273 & -0.0005 & 0.0044 & 0.000 \\
\hline
\end{tabular}

Note: Expectation and SD express the expectation value and standard deviation of the null distribution in Moran's I test. $W_{o}$ and $W_{d}$ are origin- and destination-based spatial matrixes, respectively. 


\subsubsection{Spatial Weights Based on Geographical Distance}

Here, spatial weights are based on the inverse-distance, the square of inverse-distance, and the cubic form of the inverse-distance $(p=1,2$, or 3$)$ as specified in Section 3 . The estimated model is an extended version of Equation (12), including spatial weight matrixes $(W)$.

$$
y_{o d}=\rho_{o} W_{o} y_{o d}+\rho_{d} W_{d} y_{o d}+\iota_{N} \alpha+X_{o} \beta_{o}+X_{d} \beta_{d}+d i s t_{o d} \gamma+\bar{z}_{o d, t-1} \delta+X_{i} \beta_{i}+\varepsilon \text {. }
$$

As stated previously, we use the methodology of Spatial Two-Stage Least Square (S2SLS) in the estimation to deal with potential endogeneity problems. Tables 4 and 5 show the empirical results of Equation (13). Results provide evidence that migration flows have a very complex spatial dependence as will be discussed in the following.

Table 4. S2SLS results for migration equations with spatial weights based on distance.

\begin{tabular}{|c|c|c|}
\hline $\begin{array}{l}\text { Dependent Variable: Log of Inter-Prefectural Labor Migration } \\
\text { Explanatory Variable }\end{array}$ & (1) & (2) \\
\hline Intercept & $\begin{array}{l}1.872 * \\
(0.806)\end{array}$ & $\begin{array}{c}0.421 \\
(0.315)\end{array}$ \\
\hline Unemployment rate_o & $\begin{array}{l}-0.010 \\
(0.011)\end{array}$ & $\begin{aligned}-0.067^{* * *} & (0.004)\end{aligned}$ \\
\hline Real GDP per capita_o & $\begin{array}{l}-1.117^{* * *} \\
(0.091)\end{array}$ & $\begin{aligned}-0.159 * * * \\
(0.037)\end{aligned}$ \\
\hline Real GDP per capita_d & $\begin{array}{l}-1.067 * * * \\
(0.091)\end{array}$ & $\begin{array}{l}-0.008 \\
(0.037)\end{array}$ \\
\hline No. of population_o & $\begin{array}{l}0.505^{* * *} \\
(0.041)\end{array}$ & $\begin{array}{l}-0.026 \\
(0.015)\end{array}$ \\
\hline No. of population_d & $\begin{array}{c}0.554^{* * *} \\
(0.044)\end{array}$ & $\begin{array}{c}0.022 \\
(0.016)\end{array}$ \\
\hline Average temperature_o & $\begin{array}{c}0.003 \\
(0.004)\end{array}$ & $\begin{aligned}-0.013^{* * *} & (0.002)\end{aligned}$ \\
\hline Average temperature_d & $\begin{array}{c}0.022 * * * \\
(0.005)\end{array}$ & $\begin{array}{c}0.018^{* * *} \\
(0.002)\end{array}$ \\
\hline Annual precipitation_o & $\begin{array}{c}0.143^{* *} \\
(0.047)\end{array}$ & $\begin{array}{c}0.074^{* * *} \\
(0.018)\end{array}$ \\
\hline Annual precipitation_d & $\begin{array}{c}0.080 \\
(0.046)\end{array}$ & $\begin{aligned}- & 0.089 * * * \\
& (0.018)\end{aligned}$ \\
\hline Social network effects & & $\begin{array}{l}0.946^{* * *} \\
(0.009)\end{array}$ \\
\hline Distance between prefectures & $\begin{array}{c}-0.419 \text { *** } \\
(0.030)\end{array}$ & $\begin{array}{l}-0.015 \\
(0.011)\end{array}$ \\
\hline Past intra-prefectural migration & $\begin{array}{l}0.166 \text { * } \\
(0.079)\end{array}$ & $\begin{array}{c}0.882^{* * *} \\
(0.031)\end{array}$ \\
\hline$W_{o}$ (Inverse-distance) & $\begin{array}{c}0.594^{* * *} \\
(0.035)\end{array}$ & $\begin{array}{c}0.080^{* * *} \\
(0.014)\end{array}$ \\
\hline$W_{d}$ (Inverse-distance) & $\begin{array}{c}0.558 * * * \\
(0.036)\end{array}$ & $\begin{array}{c}0.028 \\
(0.014) \\
\end{array}$ \\
\hline Sample size & 2209 & 2209 \\
\hline $\mathrm{AIC}$ & 2993.813 & -1091.322 \\
\hline
\end{tabular}

First, in Column (2) of Table 4 and Columns (3) and (4) of Table 5 (where social network effects are controlled for), all origin-based spatial matrixes $\left(W_{o}\right)$ defined on the basis of distance are reported to be statistically significant. In addition, these $W_{o}$ are positive, confirming that labor migration from $o$ to $d$ is positively influenced by migration from prefectures close to $o$ to destination $d$. Nonetheless, we fail to obtain a significant destination-based spatial dependence $\left(W_{d}\right)$. This means that flows from a prefecture $o$ to prefectures close to $d$ do not affect flows from $o$ to $d$. Among different forms of spatial matrixes, the spatial 
model with the inverse-distance $(p=1)$ fits the data best because the AIC is the smallest. Furthermore, the AIC value suggests that this spatial model explains labor migration better than the non-spatial model of Table 2 . Therefore, we select Table $4(p=1)$ to draw our main conclusions.

Table 5. S2SLS results for migration equations with spatial weights based on distance and goods flows.

\begin{tabular}{|c|c|c|c|}
\hline $\begin{array}{l}\text { Dependent Variable: Log of Inter-Prefectural } \\
\text { Labor Migration Explanatory Variable }\end{array}$ & (3) & (4) & (5) \\
\hline Intercept & $\begin{array}{l}-0.101 \\
(0.300)\end{array}$ & $\begin{array}{l}-0.149 \\
(0.300)\end{array}$ & $\begin{array}{l}-0.119 \\
(0.297)\end{array}$ \\
\hline Unemployment rate_o & $\begin{array}{l}0.010^{*} \\
(0.004)\end{array}$ & $\begin{array}{l}0.010 * \\
(0.004)\end{array}$ & $\begin{array}{l}0.010^{*} \\
(0.004)\end{array}$ \\
\hline Unemployment rate_d & $\begin{array}{c}-0.067^{* * *} \\
(0.004)\end{array}$ & $\begin{array}{c}-0.066^{* * *} \\
(0.004)\end{array}$ & $\begin{array}{c}-0.066^{* * * *} \\
(0.004)\end{array}$ \\
\hline Real GDP per capita_o & $\begin{array}{c}-0.142 * * * \\
(0.037)\end{array}$ & $\begin{array}{c}-0.142^{* * *} \\
(0.037)\end{array}$ & $\begin{array}{c}-0.170^{* * *} \\
(0.037)\end{array}$ \\
\hline Real GDP per capita_d & $\begin{array}{c}0.009 \\
(0.037)\end{array}$ & $\begin{array}{c}0.013 \\
(0.037)\end{array}$ & $\begin{array}{c}0.047 \\
(0.038)\end{array}$ \\
\hline No. of population_o & $\begin{array}{c}0.011 \\
(0.012)\end{array}$ & $\begin{array}{c}0.017 \\
(0.011)\end{array}$ & $\begin{array}{c}-0.031 \text { * } \\
(0.015)\end{array}$ \\
\hline No. of population_d & $\begin{array}{l}0.038^{* *} \\
(0.012)\end{array}$ & $\begin{array}{l}0.036^{* *} \\
(0.012)\end{array}$ & $0.054^{* * *}$ \\
\hline Average temperature_o & $\begin{array}{c}-0.012^{* * *} \\
(0.002)\end{array}$ & $\begin{array}{c}-0.012^{* * *} \\
(0.002)\end{array}$ & $\begin{array}{c}-0.013^{* * *} \\
(0.002)\end{array}$ \\
\hline Average temperature_d & $\begin{array}{c}0.019^{* * *} \\
(0.002)\end{array}$ & $\begin{array}{l}0.018^{* * *} \\
(0.002)\end{array}$ & $\begin{array}{c}0.019 * * * \\
(0.002)\end{array}$ \\
\hline Annual precipitation_o & $\begin{array}{c}0.076^{* * *} \\
(0.019)\end{array}$ & $\begin{array}{c}0.077^{* * *} \\
(0.019)\end{array}$ & $\begin{array}{c}0.073^{* * *} \\
(0.018)\end{array}$ \\
\hline Annual precipitation_d & $\begin{array}{c}-0.086^{* * *} \\
(0.019)\end{array}$ & $\begin{array}{c}-0.081^{* * *} \\
(0.019)\end{array}$ & $\begin{array}{c}-0.077^{* * * *} \\
(0.018)\end{array}$ \\
\hline Social network effects & $\begin{array}{c}0.968^{* * *} \\
(0.009)\end{array}$ & $\begin{array}{c}0.975^{* * *} \\
(0.008)\end{array}$ & $\begin{array}{c}0.951^{* * *} \\
(0.009)\end{array}$ \\
\hline Distance between prefectures & $\begin{array}{c}-0.036^{* * *} \\
(0.011)\end{array}$ & $\begin{array}{c}-0.044^{* * *} \\
(0.011)\end{array}$ & $\begin{array}{c}-0.035^{* * *} \\
(0.010)\end{array}$ \\
\hline Past intra-prefectural migration & $\begin{array}{c}0.974^{* * *} \\
(0.026)\end{array}$ & $\begin{array}{c}0.988^{* * *} \\
(0.025)\end{array}$ & $\begin{array}{c}0.943^{* * *} \\
(0.027)\end{array}$ \\
\hline$W_{o}$ (Square of inverse-distance) & $\begin{array}{c}0.026^{* * *} \\
(0.007)\end{array}$ & & \\
\hline$W_{d}$ (Square of inverse-distance) & $\begin{array}{l}-0.008 \\
(0.008)\end{array}$ & & \\
\hline$W_{o}$ (Cubic form of inverse-distance) & & $\begin{array}{l}0.013 * \\
(0.006)\end{array}$ & \\
\hline$W_{d}$ (Cubic form of inverse-distance) & & $\begin{array}{l}-0.010 \\
(0.006)\end{array}$ & \\
\hline$W_{o}$ (Past goods flow) & & & $\begin{array}{c}0.073^{* * *} \\
(0.012)\end{array}$ \\
\hline$W_{d}$ (Past goods flow) & & & $\begin{array}{l}-0.004 \\
(0.012)\end{array}$ \\
\hline $\begin{array}{c}\text { Sample size } \\
\text { AIC }\end{array}$ & $\begin{array}{c}2209 \\
-1040.679\end{array}$ & $\begin{array}{c}2209 \\
-1027.840\end{array}$ & $\begin{array}{c}2209 \\
-1079.945\end{array}$ \\
\hline
\end{tabular}

Note: ${ }^{* * *} p<0.001,{ }^{* *} p<0.01,{ }^{*} p<0.05$. Subscripts ' $\mathrm{o}$ ' and 'd' represent origin and destination regions, respectively. $W$ is a spatial weight matrix. 
Results from this table (Table 4) confirm the importance of social networks in the migration model. First, the information loss is larger when the variable is excluded. Second, as in Table 2, results of the estimation without social networks are inconsistent with expectations. For instance, in Column (1), the unemployment rate in $d$ is insignificant and income in both $o$ and $d$ is negative and significant. In contrast, in Column (2), the unemployment rate parameter in $d$ is negative and significant and the parameter of income in $d$ is insignificant. Further, the impact of temperature and precipitation in Column (2) is more in line with our expectations.

\subsubsection{Spatial Weights Based on the Flow of Goods}

Next, we use spatial weights based on the volume of traded goods between prefectures. This definition of dependence may be more appropriate in Japan where a number of metropolitan areas attract at the same time large flows of goods and of migrant workers. In addition, large flows of goods between two prefectures could be an indication of the existence of a relationship between industries (complementarity) which could justify parallel movements of migrant labor.

Estimation results are shown in Column (5) of Table 5. The general conclusions remain the same as before. Migrant workers tend to move from prefectures with a highunemployment rate to prefectures with lower unemployment. They also prefer warmer regions with low precipitation rates. Migration is more likely from low-income prefectures and is significantly and positively affected by social networks. The size of the population in the destination has a positive impact, which reflects the clustering phenomenon of labor migration around populated metropolitan areas. We also find that $W_{o}$ is statistically significant and positive. Therefore, migration flows from $o$ to destination $d$ are positively affected by flows from prefectures that have strong trade ties with $o$ to the same destination $d$. Conversely, the destination-based spatial dependence $\left(W_{d}\right)$ is found to be statistically insignificant. Finally, based on the AIC, the model performance is better than the one of Columns (3) and (4) of the same table but is inferior to the one of Column (2) in Table 4. Therefore, the definition of spatial dependence based on distance is more adequate than the one based on the volume of traded goods.

\subsubsection{Spatial Weights Based on the Economic Structure}

Finally, we define spatial dependence based on the similarity of economic structures. To capture such regional similarities, spatial weights are constructed using shares of economic sectors from the total number of firms and GDP. Results based on those measures are reported on Tables 6 and 7 , respectively. We find that $W_{o}$ and $W_{d}$ are statistically significant and positive in most cases. Furthermore, the AIC in Columns (9) and (13) is smaller than in spatial models based on geographical distance and goods flow. In addition, the smallest AIC value is the one of the model in Column (13), with a spatial weight matrix defined based on the total GDP structure. This implies that regional dependence can be more appropriately defined by the similarity in the economic structure.

Other conclusions are as follows. Social networks play a positive and significant role in labor migration. Migrants tend to move from prefectures with high unemployment and low income to prefectures with low unemployment. Relocation decisions are sensitive to weather conditions of residential sites and migrant labor tends to move from colder to warmer prefectures and from prefectures with a high precipitation rate towards those with lower precipitation levels. Finally, as opposed to previous estimations, population in the destination is found to have a negative impact. 
Table 6. S2SLS results for migration equations with spatial weights based on economic structures.

\begin{tabular}{|c|c|c|c|c|}
\hline $\begin{array}{l}\text { Dependent Variable: Log of Inter-Prefectural Labor Migration } \\
\text { Explanatory Variable }\end{array}$ & (6) & (7) & (8) & (9) \\
\hline Intercept & $\begin{array}{l}1.051^{* *} \\
(0.383)\end{array}$ & $\begin{array}{c}0.965 * * \\
(0.373)\end{array}$ & $\begin{array}{c}0.977^{* *} \\
(0.378)\end{array}$ & $\begin{array}{l}1.121 * * \\
(0.379)\end{array}$ \\
\hline Unemployment rate_o & $\begin{array}{c}0.013^{* *} \\
(0.004)\end{array}$ & $\begin{array}{c}0.015^{* * *} \\
(0.004)\end{array}$ & $\begin{array}{c}0.015^{* * *} \\
(0.004)\end{array}$ & $\begin{array}{c}0.015^{* * *} \\
(0.00)\end{array}$ \\
\hline Unemployment rate_d & $\begin{array}{c}-0.062^{* * *} \\
(0.005)\end{array}$ & $\begin{array}{c}-0.058^{* * *} \\
(0.005)\end{array}$ & $\begin{array}{c}-0.058^{* * *} \\
(0.005)\end{array}$ & $\begin{array}{c}-0.058^{* * *} \\
(0.005)\end{array}$ \\
\hline Real GDP per capita_o & $\begin{array}{l}-0.160 * * * \\
(0.037)\end{array}$ & $\begin{array}{l}-0.149 * * * \\
(0.038)\end{array}$ & $\begin{array}{l}-0.150 * * * \\
(0.038)\end{array}$ & $\begin{array}{l}-0.152 * * * \\
(0.038)\end{array}$ \\
\hline Real GDP per capita_d & $\begin{array}{l}-0.029 \\
(0.038)\end{array}$ & $\begin{array}{l}-0.021 \\
(0.039)\end{array}$ & $\begin{array}{l}-0.020 \\
(0.039)\end{array}$ & $\begin{array}{l}-0.026 \\
(0.039)\end{array}$ \\
\hline No. of population_o & $\begin{array}{l}-0.033 \\
(0.022)\end{array}$ & $\begin{array}{l}-0.037 \\
(0.024)\end{array}$ & $\begin{array}{l}-0.038 \\
(0.025)\end{array}$ & $\begin{array}{l}-0.044 \\
(0.025)\end{array}$ \\
\hline No. of population_d & $\begin{array}{l}-0.034 \\
(0.023)\end{array}$ & $\begin{array}{l}-0.043 \\
(0.024)\end{array}$ & $\begin{array}{l}-0.042 \\
(0.025)\end{array}$ & $\begin{array}{c}-0.049^{*} \\
(0.025)\end{array}$ \\
\hline Average temperature_o & $\begin{array}{c}-0.015^{* * *} \\
(0.002)\end{array}$ & $\begin{array}{c}-0.015^{* * *} \\
(0.002)\end{array}$ & $\begin{array}{c}-0.015^{* * *} \\
(0.002)\end{array}$ & $\begin{array}{c}-0.015^{* * *} \\
(0.002)\end{array}$ \\
\hline Average temperature_d & $0.013^{* * *}$ & $\begin{array}{c}0.013^{* * *} \\
(0.002)\end{array}$ & $\begin{array}{c}0.013^{* * * *} \\
(0.002)\end{array}$ & $0.012 * * *$ \\
\hline Annual precipitation_o & $\begin{array}{c}0.095^{* * *} \\
(0.019)\end{array}$ & $\begin{array}{c}0.091^{* * *} \\
(0.018)\end{array}$ & $\begin{array}{c}0.092^{* * *} \\
(0.018)\end{array}$ & $\begin{array}{c}0.093^{* * *} \\
(0.018)\end{array}$ \\
\hline Annual precipitation_d & $\begin{array}{c}-0.061^{* *} \\
(0.019)\end{array}$ & $\begin{array}{c}-0.063^{* * *} \\
(0.019)\end{array}$ & $\begin{array}{c}-0.063^{* * *} \\
(0.019)\end{array}$ & $\begin{array}{c}-0.060 * * \\
(0.019)\end{array}$ \\
\hline Social network effects & $\begin{array}{c}0.974^{* * *} \\
(0.007)\end{array}$ & $\begin{array}{c}0.969 * * * \\
(0.007)\end{array}$ & $\begin{array}{c}0.969 * * * \\
(0.007)\end{array}$ & $\begin{array}{c}0.969^{* * *} \\
(0.007)\end{array}$ \\
\hline Distance between prefectures & $\begin{array}{l}-0.045^{* * *} \\
(0.009)\end{array}$ & $\begin{array}{l}-0.052 * * * \\
(0.009)\end{array}$ & $\begin{array}{l}-0.054^{* * *} \\
(0.009)\end{array}$ & $\begin{array}{l}-0.052^{* * *} \\
(0.009)\end{array}$ \\
\hline Past intra-prefectural migration & $\begin{array}{c}0.836^{* * *} \\
(0.039)\end{array}$ & $\begin{array}{c}0.825^{* * *} \\
(0.041)\end{array}$ & $\begin{array}{c}0.825^{* * *} \\
(0.042)\end{array}$ & $\begin{array}{c}0.809^{* * *} \\
(0.042)\end{array}$ \\
\hline$W_{o}$ (Primary industry_firms) & $\begin{array}{c}0.056^{* *} \\
(0.019)\end{array}$ & & & \\
\hline$W_{d}$ (Primary industry_firms) & $\begin{array}{c}0.056^{* *} \\
(0.019)\end{array}$ & & & \\
\hline$W_{o}$ (Secondary industry_firms) & & $\begin{array}{c}0.071 * * \\
(0.022)\end{array}$ & & \\
\hline$W_{d}$ (Secondary industry_firms) & & $\begin{array}{c}0.075^{* * *} \\
(0.021)\end{array}$ & & \\
\hline$W_{o}$ (Tertiary industry_firms) & & & $\begin{array}{c}0.071^{* *} \\
(0.023)\end{array}$ & \\
\hline$W_{d}$ (Tertiary industry_firms) & & & $\begin{array}{c}0.073^{* * * *} \\
(0.022)\end{array}$ & \\
\hline$W_{o}$ (All industries_firms) & & & & $\begin{array}{c}0.076^{* * *} \\
(0.022)\end{array}$ \\
\hline$W_{d}$ (All industries_firms) & & & & $\begin{array}{c}0.078^{* * *} \\
(0.021)\end{array}$ \\
\hline Sample size & 2209 & 2209 & 2209 & 2209 \\
\hline AIC & -1081.363 & -1086.962 & -1087.114 & -1092.518 \\
\hline
\end{tabular}

Note: ${ }^{* * *} p<0.001,{ }^{* *} p<0.01,{ }^{*} p<0.05$. Subscripts ' $\mathrm{o}$ ' and ' $\mathrm{d}$ ' represent origin and destination regions, respectively. $W$ is a spatial weight matrix. 
Table 7. S2SLS results with spatial weights based on different definitions of economic structures.

\begin{tabular}{|c|c|c|c|c|}
\hline $\begin{array}{l}\text { Dependent Variable: Log of Inter-Prefectural Labor Migration } \\
\text { Explanatory Variable }\end{array}$ & (10) & (11) & (12) & (13) \\
\hline Intercept & $\begin{array}{l}1.091 \text { ** } \\
(0.378)\end{array}$ & $\begin{array}{l}1.144 \text { ** } \\
(0.372)\end{array}$ & $\begin{array}{l}1.159 * * \\
(0.376)\end{array}$ & $\begin{array}{c}1.246^{* * *} \\
(0.374)\end{array}$ \\
\hline Unemployment rate_o & $\begin{array}{l}0.013^{* *} \\
(0.004)\end{array}$ & $\begin{array}{c}0.015^{* * *} \\
(0.004)\end{array}$ & $\begin{array}{c}0.015^{* * *} \\
(0.004)\end{array}$ & $\begin{array}{c}0.015^{* * *} \\
(0.004)\end{array}$ \\
\hline Unemployment rate_d & $\begin{array}{c}-0.056^{* * *} \\
(0.005)\end{array}$ & $\begin{array}{c}-0.056^{* * *} \\
(0.005)\end{array}$ & $\begin{array}{c}-0.055^{* * *} \\
(0.005)\end{array}$ & $\begin{array}{c}-0.056^{* * *} \\
(0.005)\end{array}$ \\
\hline Real GDP per capita_o & $\begin{array}{c}-0.185^{* * *} \\
(0.038)\end{array}$ & $\begin{array}{c}-0.141^{* * *} \\
(0.038)\end{array}$ & $\begin{array}{c}-0.138^{* * *} \\
(0.038)\end{array}$ & $\begin{array}{c}-0.149^{* * *} \\
(0.037)\end{array}$ \\
\hline Real GDP per capita_d & $\begin{array}{l}-0.030 \\
(0.038)\end{array}$ & $\begin{array}{l}-0.038 \\
(0.039)\end{array}$ & $\begin{array}{l}-0.045 \\
(0.039)\end{array}$ & $\begin{array}{l}-0.038 \\
(0.039)\end{array}$ \\
\hline No. of population_o & $\begin{array}{c}0.018 \\
(0.021)\end{array}$ & $\begin{array}{l}-0.030 \\
(0.024)\end{array}$ & $\begin{array}{l}-0.022 \\
(0.025)\end{array}$ & $\begin{array}{l}-0.039 \\
(0.025)\end{array}$ \\
\hline No. of population_d & $\begin{array}{c}-0.071^{* *} \\
(0.022)\end{array}$ & $\begin{array}{c}-0.068^{* *} \\
(0.024)\end{array}$ & $\begin{array}{c}-0.076^{* *} \\
(0.024)\end{array}$ & $\begin{array}{c}-0.065^{* *} \\
(0.025)\end{array}$ \\
\hline Average temperature_o & $\begin{array}{c}-0.014^{* * *} \\
(0.002)\end{array}$ & $\begin{array}{c}-0.014^{* * *} \\
(0.002)\end{array}$ & $\begin{array}{c}-0.014^{* * *} \\
(0.002)\end{array}$ & $\begin{array}{c}-0.015^{* * *} \\
(0.002)\end{array}$ \\
\hline Average temperature_d & $\begin{array}{c}0.011^{* * *} \\
(0.002)\end{array}$ & $\begin{array}{c}0.011^{* * *} \\
(0.002)\end{array}$ & $\begin{array}{c}0.010^{* * *} \\
(0.002)\end{array}$ & $\begin{array}{c}0.011^{* * *} \\
(0.002)\end{array}$ \\
\hline Annual precipitation_o & $\begin{array}{c}0.097^{* * *} \\
(0.019)\end{array}$ & $\begin{array}{c}0.092 * * * \\
(0.018)\end{array}$ & $\begin{array}{c}0.094^{* * * *} \\
(0.018)\end{array}$ & $\begin{array}{c}0.094^{* * *} \\
(0.018)\end{array}$ \\
\hline Annual precipitation_d & $\begin{array}{c}-0.058^{* *} \\
(0.019)\end{array}$ & $\begin{array}{c}-0.058^{* *} \\
(0.019)\end{array}$ & $\begin{array}{c}-0.058^{* *} \\
(0.019)\end{array}$ & $\begin{array}{c}-0.057^{* *} \\
(0.019)\end{array}$ \\
\hline Social network effects & $\begin{array}{c}0.972 * * * \\
(0.007)\end{array}$ & $\begin{array}{c}0.968^{* * *} \\
(0.007)\end{array}$ & $\begin{array}{c}0.968^{* * *} \\
(0.007)\end{array}$ & $\begin{array}{c}0.969 * * * \\
(0.007)\end{array}$ \\
\hline Distance between prefectures & $\begin{array}{c}-0.047^{* * *} \\
(0.009)\end{array}$ & $\begin{array}{c}-0.054^{* * *} \\
(0.009)\end{array}$ & $\begin{array}{c}-0.055^{* * *} \\
(0.009)\end{array}$ & $\begin{array}{c}-0.053^{* * *} \\
(0.009)\end{array}$ \\
\hline Past intra-prefectural migration & $\begin{array}{c}0.840^{* * * *} \\
(0.037)\end{array}$ & $\begin{array}{c}0.802 * * * \\
(0.041)\end{array}$ & $\begin{array}{c}0.801^{* * *} \\
(0.042)\end{array}$ & $\begin{array}{c}0.793^{* * *} \\
(0.041)\end{array}$ \\
\hline$W_{o}$ (Primary industry_GDP) & $\begin{array}{c}0.004 \\
(0.019)\end{array}$ & & & \\
\hline$W_{d}$ (Primary industry_GDP) & $\begin{array}{c}0.094^{* * *} \\
(0.018)\end{array}$ & & & \\
\hline$W_{o}$ (Secondary industry_GDP) & & $\begin{array}{c}0.065^{* *} \\
(0.022)\end{array}$ & & \\
\hline$W_{d}$ (Secondary industry_GDP) & & $\begin{array}{c}0.098^{* * *} \\
(0.021)\end{array}$ & & \\
\hline$W_{o}$ (Tertiary industry_GDP) & & & $\begin{array}{l}0.057^{*} \\
(0.023)\end{array}$ & \\
\hline$W_{d}$ (Tertiary industry_GDP) & & & $\begin{array}{c}0.106^{* * *} \\
(0.021)\end{array}$ & \\
\hline$W_{o}$ (All industries_GDP) & & & & $\begin{array}{l}0.071^{* *} \\
(0.022)\end{array}$ \\
\hline$W_{d}$ (All industries_GDP) & & & & $\begin{array}{l}0.094^{* * *} \\
(0.021)\end{array}$ \\
\hline Sample size & 2209 & 2209 & 2209 & 2209 \\
\hline $\mathrm{AIC}$ & -1086.399 & -1086.279 & -1089.104 & -1093.990 \\
\hline
\end{tabular}

Note: ${ }^{* * *} p<0.001,{ }^{* *} p<0.01,{ }^{*} p<0.05$. Subscripts 'o' and 'd' represent origin and destination regions, respectively. $W$ is a spatial weight matrix.

\section{Discussion}

Results from the empirical estimations reveal the most important motivations in movement decisions of labor. Overall, we find that migrants tend to prefer destinations with warmer weather and lower precipitation rates. Prior studies that included climate variables also reached the conclusion that regions with higher temperature and less precipitation tend to attract more people (e.g., [18,19,34,82]). Regarding gravity variables, in line with theoretical expectations, we confirm that there is a negative relationship between distance 
and migration. The impact of population is however less clear. In the specifications with a spatial dependence based on distance or traded goods, population in destination is found to have a positive effect (implying migrants are attracted by populated areas). In contrast, when using a spatial matrix based on economic structures, we find that population in the destination has a negative impact. The authors of [98] argued that people prefer to move to areas near populated zones in order to avoid the higher living costs, and they confirmed that population density influenced migration negatively in Japan. This justification could provide an explanation to our results, especially that the data does show that net migration to economic centers such as Tokyo is lower than net migration to areas surrounding them (see Figure 5). Still, this negative effect of population density could only be captured in models where spatial dependence is defined by the similarity in the economic configuration. In comparison, the authors of [42] used an origin-destination flow model with distance-based spatial weights and found a positive relationship between the population in the destination and inter-prefectural migration flows. The authors of $[18,19]$ included population density instead of the population variable and found a negative relationship between migration flows and population density of the destination and a positive relationship between migration flows and the population density of neighboring areas.

Another important result of this study is the positive and significant effect of social networks (in line with the analysis in [41]). Further, the inclusion of the social networks variable improves the fit of our model and leads to empirical results that are more congruous with theoretical predictions. In particular, after social networks are accounted for, results indicate that labor tends to move from prefectures with low income and high unemployment towards to the area exhibiting relatively low unemployment, which is more in line with theoretical expectations (discussed in [63]). This result is in contrast with some other previous studies on Japanese migration that failed to find a consistent relationship between migration and economic factors. For instance, the authors of [42] found a positive relationship between inter-prefectural migration and unemployment in both the origin and destination. The author of [99] did not find a significant relationship between unemployment and migration (he also demonstrated that the change in income matters more than the actual level of income). The author of [34] did not find a significant relationship between migration and prefectural income per capita. Additionally, he noted that the explanatory power of other economic variables was reduced after human and amenity factors were included in the model. These studies used a model specification and methodology different from the approach used in this paper and did not incorporate the effect of social networks.

In addition to these findings, we argue in this paper that spatial dependence is more complicated than conventionally thought. More specifically, as opposed to previous analyses that relied on an inverse-distance-based spatial weight matrix, we find that regions are more closely linked through their economic structures. This specification of regional dependence shows that the economic similarity between "origin" prefectures and between "destination" prefectures is important in explaining migration flows. The main implication of this finding is that the economic structure is an important determinant of employment trends, which is consistent with previous labor market research [100,101]. This conclusion is also in line with recent studies on the Japanese labor market that showed a progressive decline of employment in some activities (typically in the primary and secondary sectors) and an increase in employment in some other occupations (professional and technical activities), reflecting changes in the economic structure (see [102]). Simultaneously, most of the activities that attract labor in the recent period (services industry) are agglomerated in particular areas such as the Tokyo region [103].

\section{Concluding Remarks}

This study empirically analyzes the effects of regional characteristics on inter-prefectural labor migration using spatial models of the origin-destination flows. An important finding of this paper is the fundamental role played by social networks in explaining migration flows. Further, we find that economic motivations are essential in the decision-making 
of relocators. Not only do the variables of unemployment and income play an important role in migration decisions, but regional dependence across flows is also found to be more adequately defined by economic structure than by geographical distance.

This result reflects the close relationship that exists between employment patterns and the nature of economic activities. In other words, regions that concentrate the most recent and rapidly evolving industries are those that attract the most labor. Conversely, zones that suffer from an increasing loss of the labor force are similar in terms of the economic activities they rely on. In most cases, these activities either do not provide a sufficient growth potential or they simply do not require as many workers as they used to in the past. Therefore, the recent trend of decoupling between urban and rural regions is a natural outcome of the evolution of the national economic structure and the migration decisions of labor that ensue from this evolution. However, since this decoupling process cannot be slowed down or prevented by the market forces, the intervention of the public sector is indispensable to make rural regions attractive enough to be considered as destination regions.

Well aware of the importance of addressing the rural decline issue, the Japanese government recently set regional revitalization as a key a nationwide policy. Therefore, a Comprehensive Strategy for Overcoming Population Decline and Vitalizing Local Economy has been put in place and many initiatives have been launched by the national and local governments, various companies, and organizations. For example, city councils' financial support for relocation and raising children is a widely implemented policy to attract labor migration to rural areas. Some municipalities offer support for venture companies that make use of resources in depopulating regions. Additionally, many prefectures encourage the implementation of projects that are based on IoT, AI, and other modern technologies. By way of example, the efforts of Japan's government to bring Taiwan Semiconductor Manufacturing Co. (TSMC) to build a plan in a southwestern prefecture of Kumamoto to produce semiconductors from 2024 will help lessen the global shortage of semiconductors and activate regional economies. Overall, the recent experience suggests that municipalities that managed to attract more labor force through the revitalization programs achieved their results mainly by encouraging the development of new industries and incorporating new technologies. Therefore, the imbalance in the distribution of migration flows across regions can be lowered if the discrepancy in terms of economic dynamism is reduced.

Author Contributions: Conceptualization, J.N. and K.M.; methodology, K.M.; software, K.M.; validation, J.N.; formal analysis, K.M. and L.B.; investigation, K.M. and L.B.; data curation, K.M.; writing —original draft preparation, K.M.; writing—review and editing, K.M., J.N. and L.B.; supervision, J.N.; project administration, J.N.; funding acquisition, J.N. All authors have read and agreed to the published version of the manuscript.

Funding: Murayama acknowledges financial support from the Japan Investment Advisers Association for travel expenses. This research was partially supported by the Tohoku Forum for Creativity via the thematic program "Environmental and Financial Risks".

Institutional Review Board Statement: Not applicable.

Informed Consent Statement: Not applicable.

Data Availability Statement: The data are available from the the first author upon request.

Acknowledgments: The earlier version of this paper was presented at the Annual Conference at National Chengchi University (2018), the Western Economic Association International Conference (2019), and the Japan Economic Association Conference (2019). We would like to thank Akira Hibiki, Hao-Chung Li, Steven Kivinen, and other participants of these meetings for useful comments.

Conflicts of Interest: The authors declare no conflict of interest. 


\section{Appendix A}

Table A1. Distribution of employees by industry and by prefecture (data from 2010 national Census).

\begin{tabular}{|c|c|c|c|c|c|c|c|c|c|}
\hline \multicolumn{6}{|c|}{$\%$ of Each Prefecture in the Share of Employees by Industry } & \multicolumn{4}{|c|}{$\%$ of Each Industry in the Share of Employees by Pref. } \\
\hline \multicolumn{2}{|c|}{ Primary Industry } & \multicolumn{2}{|c|}{ Secondary Industry } & \multicolumn{2}{|c|}{ Tertiary Industry } & \multirow[b]{2}{*}{ Prefecture } & Primary & \multirow{2}{*}{$\begin{array}{c}\text { Secondary } \\
\%\end{array}$} & \multirow{2}{*}{$\begin{array}{l}\text { Tertiary } \\
\quad \%\end{array}$} \\
\hline Prefecture & $\%$ & Prefecture & $\%$ & Prefecture & $\%$ & & $\%$ & & \\
\hline Hokkaido & $7.6 \%$ & Aichi-ken & $8.2 \%$ & Tokyo-to & $10.7 \%$ & Hokkaido & $7.7 \%$ & $18.1 \%$ & $74.2 \%$ \\
\hline Nagano-ken & $4.3 \%$ & Tokyo-to & $6.5 \%$ & Kanagawa-ken & $7.6 \%$ & Aomori-ken & $13.0 \%$ & $20.6 \%$ & $66.4 \%$ \\
\hline Kumamoto-ken & $3.6 \%$ & Kanagawa-ken & $6.3 \%$ & Osaka-fu & $6.6 \%$ & Iwate-ken & $12.2 \%$ & $24.6 \%$ & $63.1 \%$ \\
\hline Ibaraki-ken & $3.5 \%$ & Osaka-fu & $6.1 \%$ & Saitama-ken & $5.9 \%$ & Miyagi-ken & $5.1 \%$ & $22.6 \%$ & $72.2 \%$ \\
\hline Chiba-ken & $3.5 \%$ & Saitama-ken & $5.8 \%$ & Aichi-ken & $5.6 \%$ & Akita-ken & $10.1 \%$ & $25.1 \%$ & $64.8 \%$ \\
\hline Aomori-ken & $3.4 \%$ & Shizuoka-ken & $4.4 \%$ & Chiba-ken & $5.2 \%$ & Yamagata-ken & $10.0 \%$ & $29.5 \%$ & $60.5 \%$ \\
\hline Aichi-ken & $3.4 \%$ & Hyogo-ken & $4.4 \%$ & Hokkaido & $4.4 \%$ & Fukushima-ken & $7.9 \%$ & $30.1 \%$ & $62.0 \%$ \\
\hline Kagoshima-ken & $3.3 \%$ & Chiba-ken & $3.9 \%$ & Hyogo-ken & $4.2 \%$ & Ibaraki-ken & $6.2 \%$ & $29.8 \%$ & $64.1 \%$ \\
\hline Shizuoka-ken & $3.3 \%$ & Fukuoka-ken & $3.2 \%$ & Fukuoka-ken & $4.1 \%$ & Tochigi-ken & $5.8 \%$ & $32.0 \%$ & $62.1 \%$ \\
\hline Iwate-ken & $3.2 \%$ & Hokkaido & $3.0 \%$ & Shizuoka-ken & $2.9 \%$ & Gumma-ken & $5.5 \%$ & $31.8 \%$ & $62.6 \%$ \\
\hline Fukushima-ken & $3.0 \%$ & Ibaraki-ken & $2.8 \%$ & Hiroshima-ken & $2.3 \%$ & Saitama-ken & $1.8 \%$ & $25.3 \%$ & $72.9 \%$ \\
\hline Niigata-ken & $3.0 \%$ & Hiroshima-ken & $2.4 \%$ & Ibaraki-ken & $2.2 \%$ & Chiba-ken & $3.1 \%$ & $20.5 \%$ & $76.4 \%$ \\
\hline Fukuoka-ken & $2.8 \%$ & Gifu-ken & $2.4 \%$ & Kyoto-fu & $2.1 \%$ & Tokyo-to & $0.4 \%$ & $17.6 \%$ & $82.0 \%$ \\
\hline Miyazaki-ken & $2.5 \%$ & Niigata-ken & $2.3 \%$ & Miyagi-ken & $1.9 \%$ & Kanagawa-ken & $0.9 \%$ & $22.6 \%$ & $76.5 \%$ \\
\hline Saitama-ken & $2.4 \%$ & Nagano-ken & $2.2 \%$ & Niigata-ken & $1.8 \%$ & Niigata-ken & $6.3 \%$ & $29.4 \%$ & $64.3 \%$ \\
\hline Yamagata-ken & $2.3 \%$ & Tochigi-ken & $2.1 \%$ & Nagano-ken & $1.6 \%$ & Toyama-ken & $3.5 \%$ & $34.0 \%$ & $62.4 \%$ \\
\hline Tochigi-ken & $2.3 \%$ & Gumma-ken & $2.1 \%$ & Gifu-ken & $1.6 \%$ & Ishikawa-ken & $3.3 \%$ & $28.7 \%$ & $68.0 \%$ \\
\hline Miyagi-ken & $2.2 \%$ & Mie-ken & $2.0 \%$ & Gumma-ken & $1.5 \%$ & Fukui-ken & $4.0 \%$ & $31.9 \%$ & $64.2 \%$ \\
\hline Ehime-ken & $2.2 \%$ & Fukushima-ken & $1.9 \%$ & Tochigi-ken & $1.5 \%$ & Yamanashi-ken & $7.4 \%$ & $29.1 \%$ & $63.5 \%$ \\
\hline Gumma-ken & $2.2 \%$ & Kyoto-fu & $1.9 \%$ & Okayama-ken & $1.4 \%$ & Nagano-ken & $9.8 \%$ & $29.5 \%$ & $60.7 \%$ \\
\hline Nagasaki-ken & $2.2 \%$ & Okayama-ken & $1.7 \%$ & Fukushima-ken & $1.4 \%$ & Gifu-ken & $3.2 \%$ & $33.6 \%$ & $63.2 \%$ \\
\hline Akita-ken & $2.1 \%$ & Miyagi-ken & $1.7 \%$ & Kumamoto-ken & $1.4 \%$ & Shizuoka-ke & $4.2 \%$ & $33.7 \%$ & $62.1 \%$ \\
\hline Hyogo-ken & $2.1 \%$ & Shiga-ken & $1.6 \%$ & Mie-ken & $1.4 \%$ & Aichi-ken & $2.3 \%$ & $33.6 \%$ & $64.1 \%$ \\
\hline Hiroshima-ken & $1.8 \%$ & Toyama-ken & $1.3 \%$ & Kagoshima-ken & $1.3 \%$ & Mie-ken & $3.9 \%$ & $32.8 \%$ & $63.3 \%$ \\
\hline Okayama-ken & $1.8 \%$ & Yamaguchi-ken & $1.2 \%$ & Nagasaki-ken & $1.1 \%$ & Shiga-ken & $2.9 \%$ & $34.5 \%$ & $62.6 \%$ \\
\hline Wakayama-ken & $1.8 \%$ & Kumamoto-ken & $1.2 \%$ & Yamaguchi-ken & $1.1 \%$ & Kyoto-fu & $2.3 \%$ & $24.0 \%$ & $73.7 \%$ \\
\hline Kochi-ken & $1.7 \%$ & Yamagata-ken & $1.2 \%$ & Ehime-ken & $1.1 \%$ & Osaka-fu & $0.5 \%$ & $24.7 \%$ & $74.7 \%$ \\
\hline Oita-ken & $1.7 \%$ & Ishikawa-ken & $1.1 \%$ & Nara-ken & $1.1 \%$ & Hyogo-ken & $2.1 \%$ & $26.3 \%$ & $71.6 \%$ \\
\hline Saga-ken & $1.6 \%$ & Ehime-ken & $1.1 \%$ & Okinawa-ken & $1.1 \%$ & Nara-ken & $2.7 \%$ & $24.1 \%$ & $73.2 \%$ \\
\hline Yamaguchi-ken & $1.5 \%$ & Iwate-ken & $1.1 \%$ & Aomori-ken & $1.0 \%$ & Wakayama-ken & $9.6 \%$ & $22.4 \%$ & $68.0 \%$ \\
\hline Kanagawa-ken & $1.5 \%$ & Kagoshima-ken & $1.0 \%$ & Shiga-ken & $1.0 \%$ & Tottori-ken & $9.9 \%$ & $23.1 \%$ & $67.0 \%$ \\
\hline Mie-ken & $1.4 \%$ & Nara-ken & $1.0 \%$ & Iwate-ken & $1.0 \%$ & Shimane-ken & $8.5 \%$ & $24.0 \%$ & $67.4 \%$ \\
\hline Gifu-ken & $1.3 \%$ & Oita-ken & $0.9 \%$ & Ishikawa-ken & $1.0 \%$ & Okayama-ken & $5.0 \%$ & $28.1 \%$ & $66.9 \%$ \\
\hline Yamanashi-ken & $1.3 \%$ & Aomori-ken & $0.9 \%$ & Oita-ken & $0.9 \%$ & Hiroshima-ken & $3.4 \%$ & $26.6 \%$ & $70.0 \%$ \\
\hline Tokushima-ken & $1.2 \%$ & Nagasaki-ken & $0.9 \%$ & Miyazaki-ken & $0.9 \%$ & Yamaguchi-ken & $5.5 \%$ & $26.8 \%$ & $67.7 \%$ \\
\hline Shimane-ken & $1.2 \%$ & Fukui-ken & $0.9 \%$ & Yamagata-ken & $0.8 \%$ & Tokushima-ken & $8.8 \%$ & $24.3 \%$ & $66.9 \%$ \\
\hline Okinawa-ken & $1.2 \%$ & Akita-ken & $0.9 \%$ & Toyama-ken & $0.8 \%$ & Kagawa-ken & $5.9 \%$ & $25.5 \%$ & $68.6 \%$ \\
\hline Tottori-ken & $1.1 \%$ & Yamanashi-ken & $0.8 \%$ & Akita-ken & $0.8 \%$ & Ehime-ken & $8.3 \%$ & $24.5 \%$ & $67.2 \%$ \\
\hline Kagawa-ken & $1.1 \%$ & Kagawa-ken & $0.8 \%$ & Kagawa-ken & $0.8 \%$ & Kochi-ken & $12.4 \%$ & $17.5 \%$ & $70.0 \%$ \\
\hline Kyoto-fu & $1.1 \%$ & Miyazaki-ken & $0.8 \%$ & Wakayama-ken & $0.8 \%$ & Fukuoka-ken & $3.1 \%$ & $20.9 \%$ & $76.0 \%$ \\
\hline Tokyo-to & $0.9 \%$ & Wakayama-ken & $0.7 \%$ & Saga-ken & $0.7 \%$ & Saga-ken & $9.5 \%$ & $24.2 \%$ & $66.2 \%$ \\
\hline Osaka-fu & $0.8 \%$ & Saga-ken & $0.7 \%$ & Yamanashi-ken & $0.7 \%$ & Nagasaki-ken & $8.2 \%$ & $20.2 \%$ & $71.6 \%$ \\
\hline Toyama-ken & $0.8 \%$ & Shimane-ken & $0.6 \%$ & Fukui-ken & $0.6 \%$ & Kumamoto-ken & $10.5 \%$ & $21.2 \%$ & $68.4 \%$ \\
\hline Shiga-ken & $0.8 \%$ & Tokushima-ken & $0.6 \%$ & Kochi-ken & $0.6 \%$ & Oita-ken & $7.5 \%$ & $24.3 \%$ & $68.2 \%$ \\
\hline Ishikawa-ken & $0.8 \%$ & Okinawa-ken & $0.6 \%$ & Shimane-ken & $0.6 \%$ & Miyazaki-ken & $11.8 \%$ & $21.6 \%$ & $66.6 \%$ \\
\hline Nara-ken & $0.7 \%$ & Tottori-ken & $0.4 \%$ & Tokushima-ken & $0.6 \%$ & Kagoshima-ken & $10.4 \%$ & $19.6 \%$ & $70.0 \%$ \\
\hline Fukui-ken & $0.7 \%$ & Kochi-ken & $0.4 \%$ & Tottori-ken & $0.5 \%$ & Okinawa-ken & $5.4 \%$ & $15.4 \%$ & $79.2 \%$ \\
\hline
\end{tabular}




\section{Appendix B}

Table A2. Percentage of each activity in the 2005-2010 inflow of migrants by prefecture.

\begin{tabular}{|c|c|c|c|c|c|c|c|c|c|c|c|c|c|c|c|c|c|c|c|c|}
\hline Prefect & A & B & $\mathrm{C}$ & D & $\mathbf{E}$ & $\mathbf{F}$ & G & $\mathbf{H}$ & I & $\mathbf{J}$ & $\mathbf{K}$ & $\mathbf{L}$ & $\mathbf{M}$ & $\mathbf{N}$ & $\mathrm{O}$ & $\mathbf{P}$ & $\mathbf{Q}$ & $\mathbf{R}$ & $S$ & $\mathrm{~T}$ \\
\hline okyo-to & 0 . & & & & & $0.5 \%$ & $12.3 \%$ & 3. & 10. & & & $6.1 \%$ & $7.2 \%$ & & $4.5 \%$ & $8.1 \%$ & $0.2 \%$ & $5.4 \%$ & $5.1 \%$ & $4.4 \%$ \\
\hline Canagawa-ken & & & & & & & & & & & & $6.7 \%$ & $6.6 \%$ & & $4.7 \%$ & $8.4 \%$ & & $5.1 \%$ & $4.5 \%$ & $2.7^{\circ}$ \\
\hline -ken & & & & & & & $7.6 \%$ & & & & & $4.9 \%$ & $5.9 \%$ & & $4.1 \%$ & $8.8 \%$ & 0.2 & $5.6 \%$ & $5.3 \%$ & 3.8 \\
\hline hiba-ken & 0.4 & & & & & $0.4 \%$ & $9.2 \%$ & & & & & $.9 \%$ & $5.8 \%$ & & $4.0 \%$ & $8.1 \%$ & 0.2 & $5.7 \%$ & $5.7 \%$ & $2.7 \%$ \\
\hline saka-fu & 0 . & & & & 16.5 & $0.6 \%$ & $6.1 \%$ & & 19.4 & & 2.0 & $4.7 \%$ & $6.7 \%$ & & $5.0 \% 1$ & $10.1 \%$ & 0 & $4.9 \%$ & $3.2 \%$ & $3.1 \%$ \\
\hline ken & & & & & & $0.6 \%$ & $4.0 \%$ & & & & & $4.2 \%$ & $5.8 \%$ & & & $6.9 \%$ & & $4.0 \%$ & $3.4 \%$ & $3.2^{\circ}$ \\
\hline Hyogo-ken & & & & & & & $4.3 \%$ & & & & & $5.3 \%$ & $6.5 \%$ & & & & & $4.3 \%$ & $4.3 \%$ & $2.8 \%$ \\
\hline ukuoka-ken & & & & & & & $4.6 \%$ & & & & & $3.6 \%$ & $7.4 \%$ & & & & & $5.1 \%$ & $6.8 \%$ & $2.9 \%$ \\
\hline hizuoka-ken & 0.7 & & & & 25.7 & $0.7 \%$ & $2.4 \%$ & & & & & $5.2 \%$ & $7.4 \%$ & & $4.8 \%$ & $9.2 \%$ & 0.3 & $3.8 \%$ & $7.1 \%$ & $1.6 \%$ \\
\hline $\mathrm{fu}$ & 0.6 & & & & & $0.6 \%$ & $3.3 \%$ & & & & & $4.1 \%$ & $12.4 \%$ & & & $11.6 \%$ & & $4.1 \%$ & $6.6 \%$ & $3.5 \%$ \\
\hline or & & & & & & & $3.9 \%$ & & & & & $.5 \%$ & $5.2 \%$ & & $\%$ & $8.1 \%$ & & $\%$ & $5.9 \%$ & $3.2^{\circ}$ \\
\hline & & & & & & & $3.3 \%$ & & & & & $.5 \%$ & $6.0 \%$ & & & $9.1 \%$ & & $4.0 \%$ & $8.9 \%$ & $2.5 \%$ \\
\hline Tiv & & & & & & $1.5 \%$ & $4.1 \%$ & 3.7 & & & & $3.8 \%$ & $7.4 \%$ & 3.3 & $5.7 \%$ & $9.5 \%$ & & $5.1 \%$ & $7.8 \%$ & $2.0 \%$ \\
\hline aldo & & & & $-\infty 0^{-1}$ & 8.1 & $0.5 \%$ & $4.6 \%$ & 3.8 & & 5.2 & & $3.8 \%$ & $6.7 \%$ & 3. & $5.7 \%$ & $9.5 \%$ & 0.3 & $5.9 \%$ & 促 & o $2.6^{\circ}$ \\
\hline 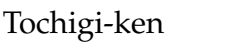 & & & & & & & $2.5 \%$ & & & & & $.3 \%$ & $7.2 \%$ & & $\%$ & 8. & & $.4 \%$ & $4.9 \%$ & $2.4^{\circ}$ \\
\hline & & & & & & & $2.7 \%$ & & & & & $3.3 \%$ & $8.3 \%$ & & & & & 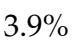 & $4.7 \%$ & $4.2 \%$ \\
\hline en & & & & & & & $2.1 \%$ & & & & & $4.3 \%$ & $7.2 \%$ & & $4.9 \%$ & 8.7 & & $3.6 \%$ & $3.8 \%$ & $3.1^{\circ}$ \\
\hline as & & & & & & $0.8 \%$ & $2.9 \%$ & & & & & $4.2 \%$ & $10.2 \%$ & & & & & $.6 \%$ & $4.3 \%$ & $2.4 \%$ \\
\hline en & & & & & & $\%$ & $1.8 \%$ & 4. & & & & $3.5 \%$ & $5.7 \%$ & & $\%$ & $7.1 \%$ & 0 . & $4.3 \%$ & $4.4 \%$ & $2.8^{\circ}$ \\
\hline & & & & & & & $2.3 \%$ & & & & & $\%$ & $7.7 \%$ & & & & & 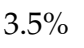 & 4 & $2.4 \%$ \\
\hline & & & & & & & $2.4 \%$ & & & & & $3.3 \%$ & $7.6 \%$ & & & & & $4.5 \%$ & $9.4 \%$ & $1.9 \%$ \\
\hline if & & & & & & $0.8 \%$ & $2.6 \%$ & & & & & $.8 \%$ & $7.3 \%$ & & $\%$ & 9. & & $.2 \%$ & $5.6 \%$ & $1.8 \%$ \\
\hline $11 \xi$ & & & & & & $2.1 \%$ & $2.8 \%$ & & & & 1. & $3.9 \%$ & $6.7 \%$ & & 1 & 10 & & $\%$ & $6.9 \%$ & $2.0 \%$ \\
\hline -ken & & & & & & 1.6 & 2.2 & & & & & $3.3 \%$ & $7.3 \%$ & & & & & & 9. & $2.4^{\circ}$ \\
\hline & & & & & & & $3.9 \%$ & & & & & $4.9 \%$ & $6.8 \%$ & & & & & & $\%$ & $2.8 \%$ \\
\hline & & & & & & & $2.3 \%$ & & & & & $.5 \%$ & $6.4 \%$ & & & & & $4.6 \%$ & $5.7 \%$ & $2.2 \%$ \\
\hline & & & & & & & 2.1 & & & & & $1 \%$ & $8.0 \%$ & & & & & & & $1.5^{\circ}$ \\
\hline 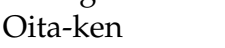 & & & & & & 1.2 & $2.4 \%$ & & & & & $3.2 \%$ & $7.4 \%$ & & 1 & & & $3.9 \%$ & 7. & $1.9^{\circ}$ \\
\hline & & & & & & & 2.0 & & & & & $3.2 \%$ & $6.6 \%$ & & & & & & & $21^{\circ}$ \\
\hline & & & & & & & 4 & & & & & & & & & & & $\%$ & $\%$ & $2.5 \%$ \\
\hline & & & & & & $1.2 \%$ & $3.3 \%$ & & & & & $.4 \%$ & $6.8 \%$ & & & 12 & & 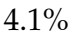 & 5. & $1.4 \%$ \\
\hline & & & & & & $1.3 \%$ & $3.3 \%$ & & & & & $3.1 \%$ & $6.9 \%$ & & 1 & 10 & & $4.1 \%$ & 8. & $1.7^{\circ}$ \\
\hline & & & & & & & 2.6 & & & & & o & 6. & & & & & & & 1.9 \\
\hline & & & & & & & & & & & & & & & & & & & $\pi$ & $4.1^{\circ}$ \\
\hline & & & & & & $1.0 \%$ & $2.7 \%$ & & & & & $3.9 \%$ & $6.7 \%$ & & & & & 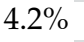 & $7.1 \%$ & $1.2^{\circ}$ \\
\hline & & & & & 8.6 & $1.8 \%$ & $2.2 \%$ & & & & & $4.4 \%$ & $5.1 \%$ & & 1 & 10. & & 4. & 17. & o $1.7^{\circ}$ \\
\hline & & & & & & & 2.2 & & & & & $3.2 \%$ & $6.8 \%$ & & & & & & $8.2 \%$ & $1.6^{\circ}$ \\
\hline$n$ & & & & & & & 2.8 & & & & & & & & & & & & $5.1 \%$ & $1.5 \%$ \\
\hline & & & & & & & $3.4 \%$ & & & & & $3.6 \%$ & $8.5 \%$ & & o & $8.9 \%$ & 0.3 & $\%$ & $4.4 \%$ & $1.8 \%$ \\
\hline & & & & & & & 2.5 & & & & & $3.8 \%$ & $7.9 \%$ & & 6.0 & 11.6 & 0 . & 3. & $8.7 \%$ & $1.5^{\circ}$ \\
\hline & & & & & & & $2.5 \%$ & & & & & $4.3 \%$ & $7.3 \%$ & & & 14. & & & $8.0 \%$ & $1.6 \%$ \\
\hline & & & & & & & 2.6 & & & & & & $6.8 \%$ & & & & & & & $1.2^{\circ}$ \\
\hline & & & & & & & $2.3 \%$ & & & & & & $7.7 \%$ & & & & & & $7.5 \%$ & $1.6 \%$ \\
\hline & & & & & 16.2 & $3.9 \%$ & $2.6 \%$ & & & & & $4.7 \%$ & $7.0 \%$ & 3.5 & $5.7 \% 1$ & 10.4 & & $5.9 \%$ & $5.6 \%$ & $1.4 \%$ \\
\hline & 1.7 & & & & 13. & 1.3 & $2.7 \%$ & 2.8 & & 5.8 & & $4.0 \%$ & $8.4 \%$ & 3.5 & 1 & 11. & 1. & 4. & $9.4 \%$ & $2.6 \%$ \\
\hline & & & & & 10. & 0.6 & 2.6 & 3.5 & & & & 4 & $7.2 \%$ & & & & & & & $3.0^{\circ}$ \\
\hline ou & & & & 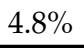 & $-s$ & $0.8 \%$ & $3.0 \%$ & 2.8 & & & & $3.9 \%$ & $8.2 \%$ & & & & & & & 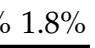 \\
\hline
\end{tabular}

Note: Data from the 2010 Japan National Census. A: Agriculture and forestry; B: Fisheries; C: Mining and quarrying of stone and gravel; D: Construction; E: manufacturing; F: Electricity, Gas, Heat supply and Water; G: Information and communications; H: Transport and postal activities; I: Wholesale and retail trade; J: Finance and insurance; K: Real estate and goods rental, leasing; L: Scientific research, professional and technical services; M: Accomodations, eating and drinking services; N: Living-related and personal, amusement services; O: Education, learning support; P: Medical, health care and welfare; R: Services, N.E.C.; S: Public Affairs; T: Unclassifiable industry. 


\section{Appendix C}

Table A3. Percentage of each prefecture in the 2005-2010 inflow of migrants by activity.

\begin{tabular}{|c|c|c|c|c|c|c|c|c|c|c|c|c|c|c|c|c|c|c|c|c|}
\hline Prefecture & A & B & $\mathrm{C}$ & D & E & $\mathbf{F}$ & G & $\mathbf{H}$ & I & $\mathbf{J}$ & K & $\mathbf{L}$ & $\mathbf{M}$ & $\mathbf{N}$ & $\mathbf{O}$ & $\mathbf{P}$ & Q & $\mathbf{R}$ & $\mathrm{S}$ & $\mathbf{T}$ \\
\hline Tokyo-to & $1.7 \%$ & $1.1 \%$ & $16.6 \%$ & $12.1 \%$ & $10.1 \%$ & $9.6 \%$ & $30.0 \%$ & $14.4 \%$ & $14.3 \%$ & $20.2 \%$ & $21.2 \%$ & $19.0 \%$ & $15.8 \%$ & $15.2 \%$ & $14.3 \%$ & $13.1 \%$ & $10.1 \%$ & $17.4 \%$ & $13.1 \%$ & $23.0 \%$ \\
\hline Kanagawa-ken & $1.8 \%$ & $1.5 \%$ & $7.0 \%$ & $8.9 \%$ & $9.6 \%$ & $4.9 \%$ & $17.4 \%$ & $9.9 \%$ & $8.9 \%$ & $9.0 \%$ & $12.0 \%$ & $13.4 \%$ & $9.2 \%$ & $9.3 \%$ & $9.5 \%$ & $8.7 \%$ & $5.1 \%$ & $10.4 \%$ & $7.5 \%$ & $8.9 \%$ \\
\hline Saitama-ken & $2.1 \%$ & $0.4 \%$ & $3.6 \%$ & $8.7 \%$ & $6.5 \%$ & $3.8 \%$ & $8.5 \%$ & $8.2 \%$ & $7.3 \%$ & $6.4 \%$ & $8.7 \%$ & $7.1 \%$ & $6.0 \%$ & $7.2 \%$ & $6.0 \%$ & $6.5 \%$ & $5.9 \%$ & $8.3 \%$ & $6.3 \%$ & $9.0 \%$ \\
\hline Chiba-ken & $3.5 \%$ & $3.7 \%$ & $5.8 \%$ & $7.6 \%$ & $5.2 \%$ & $3.9 \%$ & $9.6 \%$ & $10.1 \%$ & $6.6 \%$ & $7.1 \%$ & $7.8 \%$ & $6.5 \%$ & $5.5 \%$ & $7.4 \%$ & $5.4 \%$ & $5.6 \%$ & $4.6 \%$ & $7.8 \%$ & $6.3 \%$ & $6.0 \%$ \\
\hline Osaka-fu & $1.0 \%$ & $0.3 \%$ & $0.5 \%$ & $6.0 \%$ & $6.2 \%$ & $4.8 \%$ & $5.9 \%$ & $6.6 \%$ & $7.0 \%$ & $6.8 \%$ & $7.3 \%$ & $5.9 \%$ & $5.9 \%$ & $6.1 \%$ & $6.3 \%$ & $6.5 \%$ & $3.3 \%$ & $6.4 \%$ & $3.3 \%$ & $6.4 \%$ \\
\hline Aichi-ken & $1.9 \%$ & $0.9 \%$ & $1.4 \%$ & $5.5 \%$ & $10.3 \%$ & $5.1 \%$ & $3.6 \%$ & $6.2 \%$ & $5.9 \%$ & $4.9 \%$ & $4.4 \%$ & $5.0 \%$ & $4.8 \%$ & $4.8 \%$ & $4.8 \%$ & $4.2 \%$ & $2.5 \%$ & $4.9 \%$ & $3.3 \%$ & $6.3 \%$ \\
\hline Hyogo-ken & $2.0 \%$ & $1.5 \%$ & $1.3 \%$ & $3.5 \%$ & $4.9 \%$ & $4.1 \%$ & $2.8 \%$ & $4.1 \%$ & $4.1 \%$ & $4.5 \%$ & $4.4 \%$ & $4.3 \%$ & $3.7 \%$ & $3.9 \%$ & $4.2 \%$ & $4.4 \%$ & $3.0 \%$ & $3.6 \%$ & $2.9 \%$ & $3.8 \%$ \\
\hline Fukuoka-ken & $2.0 \%$ & $2.0 \%$ & $3.2 \%$ & $4.3 \%$ & $2.5 \%$ & $4.4 \%$ & $2.8 \%$ & $4.4 \%$ & $4.9 \%$ & $4.1 \%$ & $3.9 \%$ & $2.8 \%$ & $4.1 \%$ & $4.1 \%$ & $3.7 \%$ & $4.5 \%$ & $3.4 \%$ & $4.1 \%$ & $4.5 \%$ & $3.8 \%$ \\
\hline ka-ken & $2.7 \%$ & $5.7 \%$ & $1.9 \%$ & $2.7 \%$ & $4.2 \%$ & $2.7 \%$ & $1.0 \%$ & $2.1 \%$ & $2.3 \%$ & $2.1 \%$ & $2.1 \%$ & $2.8 \%$ & $2.9 \%$ & $2.7 \%$ & $2.7 \%$ & $2.6 \%$ & $2.8 \%$ & $2.2 \%$ & $3.2 \%$ & $1.4 \%$ \\
\hline Kyot & $1.9 \%$ & $0.5 \%$ & $0.6 \%$ & $1.4 \%$ & $2.1 \%$ & $2.0 \%$ & $1.2 \%$ & $1.8 \%$ & $2.2 \%$ & $1.6 \%$ & $1.9 \%$ & $2.0 \%$ & $4.2 \%$ & $2.3 \%$ & $4.3 \%$ & $2.9 \%$ & $1.9 \%$ & $2.0 \%$ & $2.6 \%$ & $2.8 \%$ \\
\hline Ibaraki-ken & $2.9 \%$ & $1.8 \%$ & $1.3 \%$ & $2.1 \%$ & $3.2 \%$ & $1.8 \%$ & $1.4 \%$ & $2.1 \%$ & $1.8 \%$ & $1.4 \%$ & $1.5 \%$ & $4.3 \%$ & $1.7 \%$ & $2.2 \%$ & $2.3 \%$ & $1.9 \%$ & $2.1 \%$ & $1.9 \%$ & $2.2 \%$ & $2.4 \%$ \\
\hline Hiroshima-ken & $1.7 \%$ & $0.8 \%$ & $0.4 \%$ & $2.4 \%$ & $2.4 \%$ & $2.9 \%$ & $1.2 \%$ & $1.9 \%$ & $2.7 \%$ & $2.1 \%$ & $1.9 \%$ & $1.5 \%$ & $1.9 \%$ & $1.8 \%$ & $2.1 \%$ & $2.1 \%$ & $2.3 \%$ & $1.8 \%$ & $3.3 \%$ & $1.8 \%$ \\
\hline Miyagi-ken & $1.2 \%$ & $4.4 \%$ & $0.7 \%$ & $2.3 \%$ & $1.2 \%$ & $4.0 \%$ & $1.2 \%$ & $1.8 \%$ & $2.4 \%$ & $2.0 \%$ & $2.0 \%$ & $1.5 \%$ & $2.0 \%$ & $1.8 \%$ & $2.2 \%$ & $1.9 \%$ & $2.1 \%$ & $2.0 \%$ & $2.5 \%$ & $1.3 \%$ \\
\hline Hokkaido & $9.8 \%$ & $8.3 \%$ & $7.2 \%$ & $1.7 \%$ & $0.8 \%$ & $1.2 \%$ & $1.3 \%$ & $1.6 \%$ & $1.8 \%$ & $2.0 \%$ & $1.7 \%$ & $1.3 \%$ & $1.6 \%$ & $1.5 \%$ & $2.0 \%$ & $1.7 \%$ & $1.8 \%$ & $2.1 \%$ & $3.1 \%$ & $1.5 \%$ \\
\hline Tochigi-ken & $2.1 \%$ & $0.4 \%$ & $1.8 \%$ & $1.4 \%$ & $2.4 \%$ & $1.0 \%$ & $0.6 \%$ & $1.2 \%$ & $1.4 \%$ & $1.0 \%$ & $0.9 \%$ & $2.5 \%$ & $1.5 \%$ & $1.5 \%$ & $1.3 \%$ & $1.3 \%$ & $1.4 \%$ & $1.1 \%$ & $1.2 \%$ & $1.2 \%$ \\
\hline Okayama-ken & $2.1 \%$ & $0.3 \%$ & $1.9 \%$ & $1.3 \%$ & $1.3 \%$ & $1.2 \%$ & $0.6 \%$ & $1.2 \%$ & $1.5 \%$ & $1.3 \%$ & $1.0 \%$ & $0.9 \%$ & $1.6 \%$ & $1.2 \%$ & $1.7 \%$ & $1.6 \%$ & $1.7 \%$ & $1.1 \%$ & $1.0 \%$ & $1.9 \%$ \\
\hline Shiga-ken & $1.1 \%$ & $0.5 \%$ & $0.6 \%$ & $0.9 \%$ & $2.9 \%$ & $1.0 \%$ & $0.4 \%$ & $1.1 \%$ & $1.0 \%$ & $0.7 \%$ & $0.9 \%$ & $1.2 \%$ & $1.4 \%$ & $1.3 \%$ & $1.3 \%$ & $1.2 \%$ & $0.9 \%$ & $1.0 \%$ & $0.9 \%$ & $1.4 \%$ \\
\hline Nagano-ken & $6.1 \%$ & $0.2 \%$ & $0.9 \%$ & $1.1 \%$ & $1.6 \%$ & $1.5 \%$ & $0.6 \%$ & $1.0 \%$ & $1.3 \%$ & $1.2 \%$ & $1.0 \%$ & $1.1 \%$ & $1.9 \%$ & $1.3 \%$ & $1.4 \%$ & $1.6 \%$ & $2.8 \%$ & $1.0 \%$ & $1.0 \%$ & $1.1 \%$ \\
\hline Mi & $1.7 \%$ & $2.7 \%$ & $1.0 \%$ & $1.5 \%$ & $2.9 \%$ & $1.2 \%$ & $0.4 \%$ & $1.3 \%$ & $1.0 \%$ & $0.9 \%$ & $0.7 \%$ & $1.0 \%$ & $1.1 \%$ & $1.4 \%$ & $1.1 \%$ & $1.0 \%$ & $1.3 \%$ & $1.2 \%$ & $1.0 \%$ & $1.3 \%$ \\
\hline $\mathrm{Gu}$ & $2.9 \%$ & $0.2 \%$ & $0.3 \%$ & $0.9 \%$ & $2.1 \%$ & $1.0 \%$ & $0.5 \%$ & $1.1 \%$ & $1.2 \%$ & $1.0 \%$ & $0.8 \%$ & $0.9 \%$ & $1.4 \%$ & $1.4 \%$ & $1.1 \%$ & $1.2 \%$ & $1.2 \%$ & $0.9 \%$ & $1.0 \%$ & $1.0 \%$ \\
\hline $\mathrm{Ku}$ & $2.9 \%$ & $2.0 \%$ & $0.4 \%$ & $1.0 \%$ & $1.0 \%$ & $1.5 \%$ & $0.4 \%$ & $1.0 \%$ & $1.1 \%$ & $1.0 \%$ & $0.8 \%$ & $0.8 \%$ & $1.2 \%$ & $1.1 \%$ & $1.2 \%$ & $1.6 \%$ & $2.4 \%$ & $1.1 \%$ & $1.8 \%$ & $0.7 \%$ \\
\hline Gift & $1.5 \%$ & $0.6 \%$ & $0.6 \%$ & $1.3 \%$ & $1.7 \%$ & $1.3 \%$ & $0.5 \%$ & $1.2 \%$ & $1.1 \%$ & $0.9 \%$ & $0.7 \%$ & $0.9 \%$ & $1.2 \%$ & $1.4 \%$ & $1.2 \%$ & $1.2 \%$ & $1.7 \%$ & $1.0 \%$ & $1.1 \%$ & $0.7 \%$ \\
\hline $\mathrm{Nii}$ & $2.2 \%$ & $1.3 \%$ & $16.4 \%$ & $2.0 \%$ & $0.9 \%$ & $3.3 \%$ & $0.5 \%$ & $1.0 \%$ & $1.2 \%$ & $1.1 \%$ & $0.8 \%$ & $0.9 \%$ & $1.1 \%$ & $1.2 \%$ & $1.4 \%$ & $1.2 \%$ & $2.8 \%$ & $1.1 \%$ & $1.3 \%$ & $0.8 \%$ \\
\hline ma-ken & $5.1 \%$ & $9.0 \%$ & $3.5 \%$ & $1.2 \%$ & $0.5 \%$ & $2.2 \%$ & $0.4 \%$ & $1.0 \%$ & $1.1 \%$ & $0.9 \%$ & $0.7 \%$ & $0.7 \%$ & $1.1 \%$ & $1.2 \%$ & $1.0 \%$ & $1.6 \%$ & $2.4 \%$ & $0.9 \%$ & $1.7 \%$ & $0.8 \%$ \\
\hline Nara & $0.8 \%$ & $0.1 \%$ & $0.1 \%$ & $0.9 \%$ & $1.0 \%$ & $1.1 \%$ & $0.6 \%$ & $0.8 \%$ & $0.9 \%$ & $0.8 \%$ & $1.0 \%$ & $1.0 \%$ & $0.9 \%$ & $0.9 \%$ & $1.3 \%$ & $1.2 \%$ & $1.0 \%$ & $1.2 \%$ & $0.8 \%$ & $0.9 \%$ \\
\hline Fukushima-ken & $2.7 \%$ & $0.7 \%$ & $1.0 \%$ & $1.3 \%$ & $1.2 \%$ & $3.9 \%$ & $0.4 \%$ & $0.9 \%$ & $1.0 \%$ & $1.0 \%$ & $0.6 \%$ & $0.7 \%$ & $0.9 \%$ & $1.2 \%$ & $1.1 \%$ & $1.1 \%$ & $2.4 \%$ & $1.0 \%$ & $1.0 \%$ & $0.7 \%$ \\
\hline Yamaguchi-ken & $1.4 \%$ & $3.3 \%$ & $1.9 \%$ & $1.1 \%$ & $1.0 \%$ & $1.0 \%$ & $0.3 \%$ & $1.0 \%$ & $1.0 \%$ & $0.9 \%$ & $0.7 \%$ & $0.6 \%$ & $1.1 \%$ & $1.0 \%$ & $1.1 \%$ & $1.2 \%$ & $1.7 \%$ & $0.8 \%$ & $1.7 \%$ & $0.5 \%$ \\
\hline Oita-ken & $2.1 \%$ & $3.2 \%$ & $2.9 \%$ & $1.0 \%$ & $1.0 \%$ & $1.4 \%$ & $0.3 \%$ & $0.7 \%$ & $0.8 \%$ & $0.7 \%$ & $0.6 \%$ & $0.6 \%$ & $0.9 \%$ & $0.9 \%$ & $0.8 \%$ & $1.2 \%$ & $1.6 \%$ & $0.7 \%$ & $1.2 \%$ & $0.6 \%$ \\
\hline ki-ken & $1.5 \%$ & $8.9 \%$ & $0.4 \%$ & $0.8 \%$ & $0.5 \%$ & $1.7 \%$ & $0.3 \%$ & $0.7 \%$ & $0.8 \%$ & $0.9 \%$ & $0.6 \%$ & $0.6 \%$ & $0.8 \%$ & $0.9 \%$ & $0.9 \%$ & $1.3 \%$ & $1.7 \%$ & $0.8 \%$ & $2.4 \%$ & $0.6 \%$ \\
\hline a-ken & $0.6 \%$ & $1.1 \%$ & $0.1 \%$ & $0.8 \%$ & $0.8 \%$ & $1.2 \%$ & $0.5 \%$ & $0.6 \%$ & $1.0 \%$ & $0.8 \%$ & $0.5 \%$ & $0.5 \%$ & $1.2 \%$ & $0.9 \%$ & $1.0 \%$ & $0.8 \%$ & $0.8 \%$ & $0.7 \%$ & $1.1 \%$ & $0.7 \%$ \\
\hline & $1.9 \%$ & $3.2 \%$ & $0.7 \%$ & $0.9 \%$ & $0.8 \%$ & $1.3 \%$ & $0.4 \%$ & $0.7 \%$ & 0. & $1.2 \%$ & $0.6 \%$ & $0.6 \%$ & $0.8 \%$ & $0.7 \%$ & $0.9 \%$ & $1.0 \%$ & $1.8 \%$ & $0.7 \%$ & $0.7 \%$ & $0.4 \%$ \\
\hline $\mathrm{Ka}$ & $1.0 \%$ & $1.6 \%$ & $0.2 \%$ & $1.0 \%$ & $0.6 \%$ & $1.5 \%$ & $0.4 \%$ & $0.7 \%$ & $1.0 \%$ & $1.0 \%$ & $0.8 \%$ & $0.5 \%$ & $0.8 \%$ & $0.8 \%$ & $0.8 \%$ & $0.9 \%$ & $1.7 \%$ & $0.7 \%$ & $1.1 \%$ & $0.5 \%$ \\
\hline $\mathrm{M}$ & $3.6 \%$ & $2.3 \%$ & $0.2 \%$ & $0.9 \%$ & $0.5 \%$ & $1.3 \%$ & $0.3 \%$ & $0.7 \%$ & $0.8 \%$ & $0.7 \%$ & $0.5 \%$ & $0.6 \%$ & $0.7 \%$ & $0.8 \%$ & $0.8 \%$ & $1.2 \%$ & $1.6 \%$ & $0.7 \%$ & $1.3 \%$ & $0.5 \%$ \\
\hline ken & $1.8 \%$ & $2.7 \%$ & $0.0 \%$ & $0.8 \%$ & $0.2 \%$ & $0.4 \%$ & $0.5 \%$ & $0.7 \%$ & $0.5 \%$ & $0.4 \%$ & $0.7 \%$ & $0.6 \%$ & $1.3 \%$ & $1.1 \%$ & $0.8 \%$ & $1.2 \%$ & $0.7 \%$ & $1.0 \%$ & $2.1 \%$ & $1.1 \%$ \\
\hline Iwa & $2.8 \%$ & $3.1 \%$ & $0.6 \%$ & $0.9 \%$ & $0.6 \%$ & $1.0 \%$ & $0.3 \%$ & $0.8 \%$ & $0.9 \%$ & $0.7 \%$ & $0.5 \%$ & $0.6 \%$ & $0.7 \%$ & $0.8 \%$ & $0.8 \%$ & $0.9 \%$ & $1.9 \%$ & $0.6 \%$ & $0.9 \%$ & $0.3 \%$ \\
\hline Aom & $2.2 \%$ & $2.7 \%$ & $2.7 \%$ & $1.3 \%$ & $0.4 \%$ & $1.7 \%$ & $0.2 \%$ & $0.6 \%$ & $0.7 \%$ & $0.7 \%$ & $0.4 \%$ & $0.6 \%$ & $0.5 \%$ & $0.6 \%$ & $0.7 \%$ & $0.7 \%$ & $1.0 \%$ & $0.6 \%$ & $2.1 \%$ & $0.4 \%$ \\
\hline Saga-ken & $1.0 \%$ & $1.6 \%$ & $0.1 \%$ & $0.7 \%$ & $0.6 \%$ & $1.7 \%$ & $0.2 \%$ & $0.8 \%$ & $0.6 \%$ & $0.5 \%$ & $0.4 \%$ & $0.4 \%$ & $0.6 \%$ & $0.9 \%$ & $0.7 \%$ & $1.0 \%$ & $1.2 \%$ & $0.7 \%$ & $0.9 \%$ & $0.4 \%$ \\
\hline Yamanashi-ken & $1.7 \%$ & $0.2 \%$ & $0.4 \%$ & $0.6 \%$ & $0.8 \%$ & $0.6 \%$ & $0.3 \%$ & $0.4 \%$ & $0.5 \%$ & $0.4 \%$ & $0.4 \%$ & $0.4 \%$ & $0.9 \%$ & $0.7 \%$ & $0.6 \%$ & $0.6 \%$ & $0.7 \%$ & $0.4 \%$ & $0.5 \%$ & $0.3 \%$ \\
\hline Toyama-ken & $0.6 \%$ & $1.6 \%$ & $0.3 \%$ & $1.0 \%$ & $0.9 \%$ & $1.5 \%$ & $0.4 \%$ & $0.5 \%$ & $0.6 \%$ & $0.8 \%$ & $0.4 \%$ & $0.5 \%$ & $0.8 \%$ & $0.7 \%$ & $0.7 \%$ & $0.6 \%$ & $0.8 \%$ & $0.5 \%$ & $0.5 \%$ & $0.4 \%$ \\
\hline Yamagata-ken & $1.6 \%$ & $0.4 \%$ & $0.6 \%$ & $0.5 \%$ & $0.6 \%$ & $0.9 \%$ & $0.2 \%$ & $0.5 \%$ & $0.6 \%$ & $0.6 \%$ & $0.4 \%$ & $0.5 \%$ & $0.7 \%$ & $0.7 \%$ & $0.7 \%$ & $0.7 \%$ & $1.5 \%$ & $0.5 \%$ & $0.9 \%$ & $0.3 \%$ \\
\hline Shimane-ken & $1.6 \%$ & $4.6 \%$ & $0.2 \%$ & $0.9 \%$ & $0.3 \%$ & $1.2 \%$ & $0.2 \%$ & $0.4 \%$ & $0.5 \%$ & $0.5 \%$ & $0.2 \%$ & $0.4 \%$ & $0.5 \%$ & $0.4 \%$ & $0.7 \%$ & $0.8 \%$ & $1.6 \%$ & $0.5 \%$ & $0.7 \%$ & $0.3 \%$ \\
\hline Akita-ken & $1.6 \%$ & $0.2 \%$ & $3.4 \%$ & $0.6 \%$ & $0.3 \%$ & $1.1 \%$ & $0.2 \%$ & $0.4 \%$ & $0.6 \%$ & $0.6 \%$ & $0.3 \%$ & $0.4 \%$ & $0.5 \%$ & $0.6 \%$ & $0.6 \%$ & $0.7 \%$ & $1.3 \%$ & $0.5 \%$ & $0.7 \%$ & $0.2 \%$ \\
\hline Wakas & $1.6 \%$ & $2.8 \%$ & $0.1 \%$ & $0.5 \%$ & $0.4 \%$ & $0.9 \%$ & $0.2 \%$ & $0.5 \%$ & $0.4 \%$ & $0.5 \%$ & $0.3 \%$ & $0.4 \%$ & $0.5 \%$ & $0.5 \%$ & $0.6 \%$ & $0.7 \%$ & $1.2 \%$ & $0.5 \%$ & $0.6 \%$ & $0.3 \%$ \\
\hline Fuk & $0.5 \%$ & $0.8 \%$ & $0.3 \%$ & $0.8 \%$ & $0.5 \%$ & $2.5 \%$ & $0.2 \%$ & $0.4 \%$ & $0.4 \%$ & $0.5 \%$ & $0.2 \%$ & $0.5 \%$ & $0.5 \%$ & $0.5 \%$ & $0.5 \%$ & $0.5 \%$ & $0.8 \%$ & $0.6 \%$ & $0.4 \%$ & $0.2 \%$ \\
\hline Tokus & $1.0 \%$ & $1.2 \%$ & $0.3 \%$ & $0.3 \%$ & $0.3 \%$ & $0.8 \%$ & $0.2 \%$ & $0.3 \%$ & $0.4 \%$ & $0.6 \%$ & $0.3 \%$ & $0.3 \%$ & $0.5 \%$ & $0.4 \%$ & $0.6 \%$ & $0.5 \%$ & $1.4 \%$ & $0.4 \%$ & $0.7 \%$ & $0.4 \%$ \\
\hline & $1.0 \%$ & $1.0 \%$ & $0.3 \%$ & & $0.2 \%$ & $0.3 \%$ & $0.2 \%$ & & $0.4 \%$ & $0.4 \%$ & $0.2 \%$ & $0.3 \%$ & $0.4 \%$ & $0.4 \%$ & $0.5 \%$ & $0.5 \%$ & $0.8 \%$ & $0.3 \%$ & $0.8 \%$ & $0.4 \%$ \\
\hline Koc & $1.7 \%$ & $3.0 \%$ & $4.5 \%$ & $0.4 \%$ & $0.1 \%$ & $0.4 \%$ & $0.2 \%$ & $0.3 \%$ & $0.4 \%$ & $0.5 \%$ & $0.2 \%$ & $0.3 \%$ & $0.4 \%$ & $0.4 \%$ & $0.5 \%$ & $0.5 \%$ & $1.0 \%$ & $0.3 \%$ & $0.7 \%$ & $0.2 \%$ \\
\hline
\end{tabular}

Note: Data from the 2010 Japan National Census. A: agriculture and forestry; B: fisheries; C: mining and quarrying of stone and gravel; D: construction; E: manufacturing; F: electricity, gas, heat supply and Water; G: information and communications; $\mathrm{H}$ : transport and postal activities; I: wholesale and retail trade; J: finance and insurance; $\mathrm{K}$ : real estate and goods rental, leasing; L: scientific research, professional and technical services; M: accommodations, eating and drinking services; $\mathrm{N}$ : living-related and personal, amusement services; $\mathrm{O}$ : education, learning support; P: medical, health care and welfare; R: services, N.E.C.; S: public Affairs; T: unclassifiable industry. 


\section{Appendix D}

Table A4. Proportion of marginal villages, population growth, economic structure, and migration flows of prefectures ranked based on population density.

\begin{tabular}{|c|c|c|c|c|c|c|c|c|c|}
\hline & Pop. Density & $\%$ of Genkai Shuraku & Pop. Growth & Primary & Secondary & Tertiary & Inflows & Outflows & Net Flows \\
\hline Hokkaido & 70.2 & $5.50 \%$ & $-3.1 \%$ & $7.7 \%$ & $18.1 \%$ & $74.2 \%$ & 118,673 & 150,355 & $-31,682$ \\
\hline Iwate-ken & 87.1 & $0.60 \%$ & $-6.1 \%$ & $12.2 \%$ & $24.6 \%$ & $63.1 \%$ & 47,094 & 63,095 & $-16,001$ \\
\hline Akita-ken & 93.3 & $2.10 \%$ & $-8.7 \%$ & $10.1 \%$ & $25.1 \%$ & $64.8 \%$ & 32,108 & 49,031 & $-16,923$ \\
\hline Shimane-ken & 107 & $2.50 \%$ & $-5.8 \%$ & $8.5 \%$ & $24.0 \%$ & $67.4 \%$ & 33,008 & 36,467 & -3459 \\
\hline Kochi-ken & 107.6 & $4.90 \%$ & $-6.1 \%$ & $12.4 \%$ & $17.5 \%$ & $70.0 \%$ & 25,426 & 33,609 & -8183 \\
\hline Yamagata-ken & 125.4 & $3.10 \%$ & $-6.0 \%$ & $10.0 \%$ & $29.5 \%$ & $60.5 \%$ & 37,508 & 51,245 & $-13,737$ \\
\hline Aomori-ken & 142.4 & $1.60 \%$ & $-6.9 \%$ & $13.0 \%$ & $20.6 \%$ & $66.4 \%$ & 46,197 & 69,505 & $-23,308$ \\
\hline Miyazaki-ken & 146.7 & $2.20 \%$ & $-3.0 \%$ & $11.8 \%$ & $21.6 \%$ & $66.6 \%$ & 49,007 & 57,922 & -8915 \\
\hline Fukushima-ken & 147.2 & $0.60 \%$ & $-4.6 \%$ & $7.9 \%$ & $30.1 \%$ & $62.0 \%$ & 65,051 & 88,438 & $-23,387$ \\
\hline Nagano-ken & 158.7 & $3.00 \%$ & $-2.8 \%$ & $9.8 \%$ & $29.5 \%$ & $60.7 \%$ & 79,714 & 88,688 & -8974 \\
\hline Tottori-ken & 167.8 & $1.10 \%$ & $-4.0 \%$ & $9.9 \%$ & $23.1 \%$ & $67.0 \%$ & 25,597 & 31,140 & -5543 \\
\hline Kagoshima-ken & 185.7 & $2.40 \%$ & $-4.5 \%$ & $10.4 \%$ & $19.6 \%$ & $70.0 \%$ & 69,864 & 81,945 & $-12,081$ \\
\hline Niigata-ken & 188.7 & $3.40 \%$ & $-4.1 \%$ & $6.3 \%$ & $29.4 \%$ & $64.3 \%$ & 70,687 & 82,013 & $-11,326$ \\
\hline Oita-ken & 188.7 & $2.10 \%$ & $-2.0 \%$ & $7.5 \%$ & $24.3 \%$ & $68.2 \%$ & 56,991 & 56,949 & 42 \\
\hline Tokushima-ken & 189.4 & $4.20 \%$ & $-4.7 \%$ & $8.8 \%$ & $24.3 \%$ & $66.9 \%$ & 27,426 & 35,093 & -7667 \\
\hline Fukui-ken & 192.4 & $2.30 \%$ & $-2.7 \%$ & $4.0 \%$ & $31.9 \%$ & $64.2 \%$ & 26,917 & 33,229 & -6312 \\
\hline Yamanashi-ken & 193.3 & $1.70 \%$ & $-2.8 \%$ & $7.4 \%$ & $29.1 \%$ & $63.5 \%$ & 40,153 & 40,774 & -621 \\
\hline Gifu-ken & 195.9 & $1.90 \%$ & $-1.3 \%$ & $3.2 \%$ & $33.6 \%$ & $63.2 \%$ & 72,319 & 88,509 & $-16,190$ \\
\hline Wakayama-ken & 212 & $1.60 \%$ & $-6.3 \%$ & $9.6 \%$ & $22.4 \%$ & $68.0 \%$ & 30,565 & 42,240 & $-11,675$ \\
\hline Yamaguchi-ken & 237.4 & $3.00 \%$ & $-5.0 \%$ & $5.5 \%$ & $26.8 \%$ & $67.7 \%$ & 64,434 & 71,143 & -6709 \\
\hline Kumamoto-ken & 245.4 & $0.90 \%$ & $-2.3 \%$ & $10.5 \%$ & $21.2 \%$ & $68.4 \%$ & 73,648 & 86,013 & $-12,365$ \\
\hline Ehime-ken & 252.1 & $3.30 \%$ & $-4.1 \%$ & $8.3 \%$ & $24.5 \%$ & $67.2 \%$ & 51,449 & 60,468 & -9019 \\
\hline Toyama-ken & 257.4 & $5.00 \%$ & $-2.5 \%$ & $3.5 \%$ & $34.0 \%$ & $62.4 \%$ & 38,456 & 42,085 & -3629 \\
\hline Okayama-ken & 273.5 & $1.10 \%$ & $-0.3 \%$ & $5.0 \%$ & $28.1 \%$ & $66.9 \%$ & 86,639 & 86,152 & 487 \\
\hline Ishikawa-ken & 279.5 & $4.00 \%$ & $-0.9 \%$ & $3.3 \%$ & $28.7 \%$ & $68.0 \%$ & 52,761 & 53,705 & -944 \\
\hline Tochigi-ken & 313.3 & $0.20 \%$ & $0.1 \%$ & $5.8 \%$ & $32.0 \%$ & $62.1 \%$ & 92,201 & 91,012 & 1189 \\
\hline Gumma-ken & 315.6 & $0.90 \%$ & $-0.8 \%$ & $5.5 \%$ & $31.8 \%$ & $62.6 \%$ & 75,852 & 78,994 & -3142 \\
\hline Mie-ken & 321 & $1.60 \%$ & $-0.1 \%$ & $3.9 \%$ & $32.8 \%$ & $63.3 \%$ & 77,746 & 78,939 & -1193 \\
\hline Miyagi-ken & 322.3 & $0.30 \%$ & $-0.7 \%$ & $5.1 \%$ & $22.6 \%$ & $72.2 \%$ & 124,701 & 127,950 & -3249 \\
\hline Hiroshima-ken & 337.4 & $2.90 \%$ & $-0.6 \%$ & $3.4 \%$ & $26.6 \%$ & $70.0 \%$ & 131,052 & 135,720 & -4668 \\
\hline Nagasaki-ken & 347.5 & $1.30 \%$ & $-5.9 \%$ & $8.2 \%$ & $20.2 \%$ & $71.6 \%$ & 56,990 & 80,407 & $-23,417$ \\
\hline Saga-ken & 348.3 & $1.00 \%$ & $-3.1 \%$ & $9.5 \%$ & $24.2 \%$ & $66.2 \%$ & 41,619 & 47,209 & -5590 \\
\hline Shiga-ken & 351.2 & $1.20 \%$ & $5.1 \%$ & $2.9 \%$ & $34.5 \%$ & $62.6 \%$ & 82,141 & 65,876 & 16,265 \\
\hline Nara-ken & 379.5 & $1.10 \%$ & $-2.9 \%$ & $2.7 \%$ & $24.1 \%$ & $73.2 \%$ & 68,047 & 79,863 & $-11,816$ \\
\hline Shizuoka-ken & 483.9 & $1.10 \%$ & $-0.1 \%$ & $4.2 \%$ & $33.7 \%$ & $62.1 \%$ & 154,093 & 154,534 & -441 \\
\hline Ibaraki-ken & 487.2 & $0.00 \%$ & $-0.5 \%$ & $6.2 \%$ & $29.8 \%$ & $64.1 \%$ & 137,789 & 131,021 & 6768 \\
\hline Kagawa-ken & 530.7 & $1.00 \%$ & $-2.6 \%$ & $5.9 \%$ & $25.5 \%$ & $68.6 \%$ & 49,139 & 52,214 & -3075 \\
\hline Kyoto-fu & 571.4 & $1.90 \%$ & $-0.3 \%$ & $2.3 \%$ & $24.0 \%$ & $73.7 \%$ & 158,320 & 158,320 & 0 \\
\hline Okinawa-ken & 611.9 & $0.00 \%$ & $5.7 \%$ & $5.4 \%$ & $15.4 \%$ & $79.2 \%$ & 47,746 & 47,221 & 525 \\
\hline Hyogo-ken & 665.6 & $0.60 \%$ & $0.7 \%$ & $2.1 \%$ & $26.3 \%$ & $71.6 \%$ & 248,936 & 249,075 & -139 \\
\hline Fukuoka-ken & 1019 & $0.40 \%$ & $1.1 \%$ & $3.1 \%$ & $20.9 \%$ & $76.0 \%$ & 250,839 & 249,069 & 1770 \\
\hline Chiba-ken & 1205.5 & $0.10 \%$ & $4.9 \%$ & $3.1 \%$ & $20.5 \%$ & $76.4 \%$ & 391,460 & 325,990 & 65,470 \\
\hline Aichi-ken & 1434.8 & $0.30 \%$ & $5.2 \%$ & $2.3 \%$ & $33.6 \%$ & $64.1 \%$ & 320,204 & 263,718 & 56,486 \\
\hline Saitama-ken & 1894.2 & $0.80 \%$ & $3.7 \%$ & $1.8 \%$ & $25.3 \%$ & $72.9 \%$ & 419,909 & 351,272 & 68,637 \\
\hline Kanagawa-ken & 3745.4 & $0.40 \%$ & $6.6 \%$ & $0.9 \%$ & $22.6 \%$ & $76.5 \%$ & 574,878 & 482,627 & 92,251 \\
\hline Osaka-fu & 4669.7 & $0.00 \%$ & $0.7 \%$ & $0.5 \%$ & $24.7 \%$ & $74.7 \%$ & 374,456 & 414,639 & $-40,183$ \\
\hline Tokyo-to & 6015.7 & $0.00 \%$ & $9.1 \%$ & $0.4 \%$ & $17.6 \%$ & $82.0 \%$ & 891,580 & 845,907 & 45,673 \\
\hline
\end{tabular}

Note: Pop density: population density per $\mathrm{km}^{2}$; \% of Genkai shuraku: share of Genkai shuraku from total villages (defined as villages with 9 inhabitants or less and over $50 \%$ of population over 65 years old); Pop growth: population growth between 2000 and 2010; primary, secondary, and tertiary represent the shares of each sector in the total number of employees; inflows, outflows, and net flows represent the flows of migrants between 2005 and 2010, based on the 2010 Japan Population Census.

\section{References}

1. Carrington, W.J.; Detragiache, E.; Vishwanath, T. Migration with Endogenous Moving Costs. Am. Econ. Rev. 1996, 86, 909-930.

2. Todaro, M. Internal Migration in Developing Countries: A Survey. In Population and Economic Change in Developing Countries; University of Chicago Press: Chicago, IL, USA, 1980; pp. 361-402. Available online: https://EconPapers.repec.org/RePEc:nbr: nberch:9668 (accessed on 24 January 2022).

3. Giguère, S. Population Decline, Employment and Prosperity: Setting the Conditions for Quality Job Creation in All Regions of Japan. Policy Res. Inst. Minist. Financ. Jpn. Public Policy Rev. 2018, 14, $25-52$.

4. Batabyal, A.; Higano, Y.; Nijkamp, P. Rural-urban dichotomies and spatial development in Asia. In New Frontiers In Regional Science: Asian Perspectives; Springer: Singapore, 2021; ISBN 9811612315.

5. Deshingkar, P.; Grimm, S. Internal Migration and Development: A Global Perspective; International Organization for Migration: Herndon, VA, USA, 2005. Available online: https://www.un-ilibrary.org/content/books/9789213630112 (accessed on 24 January 2022).

6. United Nations (Department of Economic and Social Affairs, Population Dynamics). World Urbanization Prospects. 2018. Available online: https:/ / population.un.org/wup/Country-Profiles / (accessed on 24 January 2022). 
7. Toyoda, T. Changes in regional disparities and population in Japan. Assoc. Econ. Geogr. 2013, 59, 4-26.

8. Liaw, K. Interprefectural migration and its effects on prefectural populations in Japan: An a nalysis based on the 1980 census. Can. Geogr. 1992, 36, 320-335. [CrossRef]

9. Onitsuka, K. Genkai shuraku (marginal village in Japan). In The Blackwell Encyclopedia of Sociology; Ritzer, G., Ed.; Wiley-Blackwell: Malden, MA, USA, 2007; pp. 1-4; ISBN 9781405124331.

10. Yagi, Y.; Nagai, K.; Suzuki, N.; Matous, P. A Survey of Social Support Networks in a Depopulating Japanese Village. Soc. Soc. Manag. Syst. 2012, 8, 12-4216. Available online: https://ssms.jp/pb/cont/internetjournal/912 (accessed on 24 January 2022).

11. Ministry of Agriculture, Forestry and Fisheries Agriculture; Forestry and Fisheries Policy Research Institute. Shrinking of Japanese Villages with Aging and Declining Populations. 2014. Available online: https:/ / www.maff.go.jp/primaff/koho/seminar/2014 /attach/pdf/141028_01.pdf (accessed on 24 January 2022).

12. Feldhoff, T. Shrinking communities in Japan: Community ownership of a ssets as a development potential for rural Japan? Urban Des. Int. 2013, 18, 99-109. [CrossRef]

13. Matanle, P. Towards an Asia-Pacific 'Depopulation Dividend'in the 21st century: Regional growth and shrinkage in Japan and New Zealand. Asia Pac. J. Jpn. Focus 2017, 15. Available online: https:/ / eprints.whiterose.ac.uk/114351/ (accessed on 24 January 2022).

14. Matanle, P.; Rausch, A. Japan's Shrinking Regions in the 21st Century: Contemporary Responses to Depopulation and Socioeconomic Decline; Cambria Press: Amherst, NY, USA, 2011; ISBN 1604977582.

15. Ishikawa, Y. The 1970s migration turnaround in Japan revisited: A shift-share approach. Pap. Reg. Sci. 1992, 71, 153-173. [CrossRef]

16. Ishikawa, Y. Contribution of the demographic factor to the migration turnarounds in Japan, Sweden and Canada. Int. J. Popul. Geogr. 1999, 5, 1-17. [CrossRef]

17. Tamura, K.; Sakamoto, H. Intergenerational comparison of Japan's inter-prefectural migration. AGI Work. Pap. Ser. 2016, 2016, $1-11$.

18. Kondo, K.; Okubo, T. Structural Estimation and Interregional Labour Migration: Evidence from Japan. Keio/Kyoto Joint Global COE Program, Discussion Paper Series. 2012. Available online: http://ies.keio.ac.jp/old_project/old/gcoe-econbus/pdf/dp/ DP2011-040.pdf (accessed on 24 January 2022).

19. Kondo, K.; Okubo, T. Interregional Labour Migration and Real Wage Disparities: Evidence from Japan. Pap. Reg. Sci. 2015, 94 , 67-87.

20. Yano, K.; Nakaya, T.; Ishikawa, Y. An analysis of inter-municipal migration flows in Japan using GIS and spatial interaction modeling. Geogr. Rev. Jpn. Ser. 2000, 73, 165-177. [CrossRef]

21. Fotheringham, A.; Nakaya, T.; Yano, K.; Openshaw, S.; Ishikawa, Y. Hierarchical destination choice and spatial interaction modelling: A simulation experiment. Environ. Plan. 2001, 33, 901-920. [CrossRef]

22. Kondo, K. Migration Response to High Unemployment Rates: Spatial Econometric Analysis Using Japanese Municipal Data. J. Jpn. Stat. Soc. 2015, 45, 69-98.

23. Shimizu, M. On the quantum and tempo of cumulative net migration. J. Popul. Probl. 2006, 62, 41-60.

24. Kawabe, H. Some characteristics of internal migration observed from the cohort-by-cohort analysis. J. Popul. Probl. 1985, 175, $1-15$.

25. Kawabe, H.; Liaw, K. Selective effects of marriage migrations on the population redistribution in a hierarchical regional system of Japan. Geogr. Rev. Jpn. Ser. 1994, 67, 1-14. [CrossRef]

26. Inoue, $\mathrm{T}$. Jinkogaku teki shiten kara mita wagakuni no jinko ido tenkan (Migration turnarounds in Japan: A demographic viewpoint). In Nihon Jinko Ido Raifu Kosu Chiikisei; Kokonshoin: Tokyo, Japan, 2002; pp 53-70; ISBN 4772260099.

27. Ogasawara, S. Jinko Chirigaku Nyumon (Introduction to Population Geography); Harashobo: Tokyo, Japan, 1999; 132p, ISBN 456209026X.

28. Otomo, A. Nihon no Jinko Ido-Sengo ni okeru Jinko no Chiiki Bunpu Hendo to Chiikikan Ido (Migration in Japan-Change in the Regional Distribution of Population and Interregional Migration in the Postwar Era); Okurasho Insatsukyoku: Tokyo, Japan, 1996; ISBN 4173151101.

29. Tsutsumi, M.; Tamesue, K. Intraregional Flow Problem in Spatial Econometric Model for Origin-Destination Flows. Environ. Plan. Plan. Des. 2012, 39, 1006-1015. [CrossRef]

30. LeSage, J.P.; Pace, R.K. Introduction to Spatial Econometrics; CRC Press: Boca Raton, FL, USA, 2009 ; ISBN 978420064247.

31. LeSage, J.P.; Pace, R.K. Spatial Econometric Modeling of Origin-Destination Flows. J. Reg. Sci. 2008, 48, 941-967. [CrossRef]

32. Mohamedou, N. Labor mobility within Japanese regional labor markets and spillover effects. Jpn. Econ. Rev. 2020, 1-21. [CrossRef]

33. Lam, C.; Souza, P. Estimation and selection of spatial weight matrix in a spatial lag model. J. Bus. Econ. Stat. 2020, 38, 693-710. [CrossRef]

34. Kokubun, K. What factors have caused Japanese prefectures to a ttract a larger population influx? arXiv 2020, arXiv:2009.07144.

35. Rätzel, S. Labour supply, life satisfaction, and the (dis) utility of work. Scand. J. Econ. 2012, 114, 1160-1181. [CrossRef]

36. Nagayasu, J. Regional Inflation and Industrial Structure in Monetary Union, MPRA Paper; University Library of Munich: Munich, Germany, 2012; p. 37310.

37. Nagayasu, J. Inflation and consumption of nontradable goods: Global implications from regional analysis. Int. Rev. Econ. Financ. 2017, 48, 478-491. [CrossRef] 
38. Nagayasu, J. Regional inflation, spatial locations and the Balassa-Samuelson effect: Evidence from Japan. Urban Stud. 2017, 54, 1482-1499. [CrossRef]

39. Demaria, K.; Fee, K.; Wardrip, K. Exploring a Skills-Based Approach to Occupational Mobility; Community Affairs Discussion Paper 89004; Federal Reserve Bank of Philadelphia: Philadelphia, PA, USA, 2020.

40. Elliott, R.; Lindley, J. Skill specificity and labour mobility: Occupational and sectoral dimensions. Manch. Sch. 2006, 74, 389-413. [CrossRef]

41. Ishiguro, I.; Lee, Y.; Sugiura, H.; Yamaguchi, K. Tokyoni Deru Wakamonotachi (The Brain Drain: Why Japanese Youth Move to Tokyo); Minerva: Kyoto, Japan, 2012; ISBN 4623064085.

42. Tamesue, K.; Tsutsumi, M. Dealing with Intraregional Flows in Spatial Econometric Gravity Models. In Spatial Econometric Interaction Modelin; Patuelli, R., Arbia, G., Eds.; Springer: Cham, Switzerland, 2016; ISBN-10:3319807463.

43. Statistics Bureau of Japan. Population Census. 2010. Available online: https:/ / www.e-stat.go.jp/en/stat-search/files?page=1\& toukei $=00200521 \&$ tstat $=000001039448$ (accessed on 24 January 2022).

44. Statistics Bureau of Japan. Population Census. 2015. Available online: https:/ / www.e-stat.go.jp/en/stat-search/files?page=1\& toukei $=00200521 \&$ tstat $=000001080615 \&$ year $=20150 \&$ month $=0$ (accessed on 24 January 2022).

45. Statistics Bureau of Japan. Labor Force Survey. 2021. Available online: https://www.stat.go.jp/data/roudou/pref/index.html (accessed on 24 January 2022).

46. Cabinet Office. Prefectural Statistical Tables. 2018. Available online: https://www.esri.cao.go.jp/jp/sna/data/data_list/kenmin/ files/contents/main_2018.html (accessed on 24 January 2022).

47. Carling, J.; Czaika, M.; Erdal, M. Translating migration theory into empirical propositions. In QuantMig Project Deliverable; University of Southampton: Southampton, UK, 2020; Volume 1. Available online: https://www.prio.org/publications/12526 (accessed on 24 January 2022).

48. Champion, A.; Fotheringham, S.; Rees, P.; Boyle, P.; Stillwell, J. The Determinants of Migration Flows in England: A Review of Existing Data and Evidence: A Report Prepared for the Department of the Environment, Transport and the Regions; Department of Geography, University of Newcastle upon Tyne: Newcastle, UK, 1998. Available online: http://www.geog.leeds.ac.uk/publications/ DeterminantsOfMigration/report.pdf (accessed on 24 January 2022).

49. Sjaastad, L.A. The Costs and Returns of Human Migration. J. Political Econ. 1962, 70, 80-93. [CrossRef]

50. Greenwood, M.; Hunt, G. The early history of migration research. Int. Reg. Sci. Rev. 2003, 26, 3-37. [CrossRef]

51. Stouffer, S. Intervening opportunities: A the ory relating mobility and distance. Am. Sociol. Rev. 1940, 5, 845-867. [CrossRef]

52. Stouffer, S. Intervening opportunities and competing migrants. J. Reg. Sci. 1960, 2, 1-26. [CrossRef]

53. Schneider, M. Gravity models and trip distribution theory. Pap. Reg. Sci. 1959, 5, 51-56. [CrossRef]

54. Alonso, W. A theory of movements. In Human Settlement Systems: International Perspective on Structure, Change and Public Policy; Hansen, N., Ed.; Ballinger Publishing Company: Pensacola, FL, USA, 1978; ISBN 0884101762.

55. Lenormand, M.; Bassolas, A.; Ramasco, J. Systematic comparison of trip distribution laws and models. J. Transp. Geogr. 2016, 51, 158-169. [CrossRef]

56. Lee, E. A theory of migration. Demography 1966, 3, 47-57. [CrossRef]

57. Greenwood, M.J. Internal migration in developed countries. In Handbook of Population and Family Economics; North Holland: Amsterdam, The Netherlands, 1997; Volume 1, pp. 647-720.

58. Zimmermann, K. European migration: Push and pull. Int. Reg. Sci. Rev. 1996, 19, 95-128. [CrossRef]

59. Beine, M.; Bertoli, S.; Moraga, J.F.-H. A Practitioners' Guide to Gravity Models of International Migration. World Econ. 2016, 39, 496-512. [CrossRef]

60. Fan, C. Modeling interprovincial migration in China, 1985-2000. Eurasian Geogr. Econ. 2005, 46, 165-184. [CrossRef]

61. Bodvarsson, Ö.; Van den Berg, H. The Economics of Immigration; Springer: Berlin/Heidelberg, Germany, 2013 ; ISBN 101461421152.

62. Fields, G. Place-to-place migration: Some new evidence. Rev. Econ. Stat. 1979, 61, 21-32. [CrossRef]

63. Ohta, S.; Ohkusa, Y. Regional Labor Mobility and Wage Curve in Japan. Jcer Econ. J. 1996, 32, 111-132.

64. Ohta, S. Regional Characteristics of the Japanese Youth Labour Market. Jpn. J. Labour Stud. 2005, 539, 17-33.

65. Bentivogli, C.; Pagano, P. Regional disparities and labour mobility: The euro-11 versus the USA. Labour 1999, 13, 737-760. [CrossRef]

66. Harris, J.; Todaro, M. Migration, unemployment and development: A two-sector analysis. Am. Econ. Rev. 1970, 60, 126-142.

67. Andrienko, Y.; Guriev, S. Determinants of interregional mobility in Russia. Econ. Transit. 2004, 12, 1-27. [CrossRef]

68. Marston, S. Two views of the geographic distribution of unemployment. Q. J. Econ. 1985, 100, 57-79. [CrossRef]

69. Berger, M.; Blomquist, G.; Peter, K. Compensating differentials in emerging labor and housing markets: Estimates of quality of life in Russian cities. J. Urban Econ. 2008, 63, 25-55. [CrossRef]

70. Ravenstein, E. The laws of migration. J. Stat. Soc. Lond. 1885, 48, 167-235. [CrossRef]

71. Bauer, T.; Zimmermann, K. Integrating the East: The labor market effects of immigration. In Europe's Economy Looks East: Implications for Germany and the EU; Black, S.W., Ed.; Cambridge University Press: Cambridge, UK, 1997; pp. 269-306. ISBN 100521572428.

72. Bauer, T.; Zimmermann, K. Network migration of ethnic Germans. Int. Migr. Rev. 1997, 31, 143-149. [CrossRef]

73. Curry, L. A spatial analysis of gravity flows. Reg. Stud. 1972, 6, 131-147. [CrossRef]

74. Griffith, D. Spatial structure and spatial interaction: 25 years later. Rev. Reg. Stud. 2007, 37, 28-38. [CrossRef]

75. Curry, L.; Griffith, D.; Sheppard, E. Those gravity parameters again. Reg. Stud. 1975, 9, 289-296. [CrossRef] 
76. Griffith, D.; Jones, K. Explorations into the relationship between spatial structure and spatial interaction. Environ. Plan. 1980, 12, 187-201. [CrossRef]

77. Porojan, A. Trade flows and spatial effects: The gravity model revisited. Open Econ. Rev. 2001, 12, 265-280. [CrossRef]

78. Lee, M.; Pace, R. Spatial distribution of retail sales. J. Real Estate Financ. Econ. 2005, 31, 53-69. [CrossRef]

79. Cressie, N. Statistics for Spatial Data; John Wiley \& Sons: New York, NY, USA, 2015; ISBN 9781119114611.

80. Nakagawa, S. Internal migration in to day's Japan. Geogr. Pol. 2000, 73, 127-140.

81. Ito, K. An analysis of income growth effect on the long-distance migration in postwar Japan. J. Popul. Stud. 2006, 38, 89-98. [CrossRef]

82. Sasaki, K.; Tomioka, T. Ecomomic Evaluation of Urban Amenities Including the Effects on Migration; Working Paper Series ersa02; European Regional Science Association (ERSA): Louvain-la-Neuve, Belgium, 2002; p. 131. Available online: https://ideas.repec. org/p/wiw/wiwrsa/ersa02p131.html (accessed on 24 January 2022).

83. McFadden, D. Conditional logit analysis of qualitative choice behavior. In Frontiers in Econometrics; Zarembka, P., Ed.; Academic Press: Cambridge, MA, USA, 1974; pp. 105-142; ISBN 0127761500.

84. Andersson, J.; Ubøe, J. Some Aspects of Random Utility, Extreme Value Theory and Multinomial Logit Models. Int. J. Probab. Stoch. Process. 2012, 84, 425-435. [CrossRef]

85. Bodvarsson, Ö.B.; Simpson, N.B.; Sparber, C. Migration Theory. Handb. Econ. Int. Migr. 2015, 1, 3-51.

86. Cushing, B.; Poot, J. Crossing boundaries and borders: Regional science advances in migration modelling. Pap. Reg. Sci. 2004, 83, 317-338. [CrossRef]

87. Karemera, D.; Oguledo, V.I.; Davis, B. A Gravity Model Analysis of International Migration to North America. Appl. Econ. 2000 32, 1745-1755. [CrossRef]

88. Pedersen, P.J.; Pytlikova, M.; Smith, N. Selection and Network Effects: Migration Flows into OECD Countries 1990-2000. Eur. Econ. Rev. 2008, 52, 1160-1186. [CrossRef]

89. Hunt, J. Staunching Emigration from East Germany: Age and the Determinants of Migration. J. Eur. Econ. Assoc. 2006, 4, 1014-1037. [CrossRef]

90. Hatton, T.; Tani, M. Immigration and inter-regional mobility in the UK, 1982-2000. Econ. J. 2005, 115, F342-F358. [CrossRef]

91. Maddison, D.; Bigano, A. The a menity value of the Italian climate. J. Environ. Econ. Manag. 2003, 45, 319-332. [CrossRef]

92. Yap, L.Y.L. The Attraction of Cities: A Review of the Migration Literature. J. Dev. Econ. 1977, 4, 239-264. [CrossRef]

93. Hugo, G.J. Village-community ties, village norms, and ethnic and social networks: A review of evidence from the third world. In Migration Decision Making: Multidisciplinary Approaches to Micro-Level Studies in Developed and Developing Countries; De Jong, G.F., Gardner, R.W., Eds.; Pergamon Press: New York, NY, USA, 1981; pp. 186-224.

94. Arango, J. Explaining migration: A critical view. Int. Soc. Sci. J. 2000, 52, 283-296. [CrossRef]

95. LeSage, J.; Fischer, M. Spatial econometric methods for modeling origin-destination flows. In Handbook of Applied Spatial Analysis; Springer: Berlin/Heidelberg, Germany, 2010; pp 409-433; ISBN 978-3-642-03646-0. [CrossRef]

96. Kelejian, H.; Piras, G. Spatial Econometrics; Academic Press: London, UK, 2017.

97. Badinger, H.; Egger, P. Estimation of Higher-Order Spatial Autoregressive Cross-Section Models with Heteroscedastic Disturbances. Pap. Reg. Sci. 2011, 90, 213-235. [CrossRef]

98. Barro, R.T.; Sala-I-Martin, X. Regional growth and migration: A Japan-United States comparison. J. Jpn. Int. Econ. 1992, 6, 312-346. [CrossRef]

99. Yonemoto, K. Overpopulation and reference-dependent preferences: Does internal migration in Japan sctually satisfy people? In Rural-Urban Dichotomies And Spatial Development in Asia; Springer: Singapore, 2021; pp. 43-68; ISBN 109811612315.

100. Allen, J.; Velden, R. Educational mismatches versus skill mismatches: Effects on wages, job satisfaction, and on-the-job search. Oxf. Econ. Pap. 2001, 53, 434-452. [CrossRef]

101. Van Reenen, J. Wage inequality, technology and trade: 21st century evidence. Labour Econ. 2011, 18, 730-741. [CrossRef]

102. Japan Institute for Labour Policy and Training. Labor Situation in Japan and Its Analysis: General Overview 2015/2016. 2016. Available online: https:/ / www.jil.go.jp/english/lsj/general/2015-2016.html (accessed on 24 January 2022).

103. Umetani, K.; Yokoyama, T. Concentration of population in Tokyo: A survey. National Graduate Institute for Policy Studies. GRIPS Discussion Papers 15-21. 2015. Available online: https://ideas.repec.org/p/ngi/dpaper/15-21.html (accessed on 24 January 2022). 